


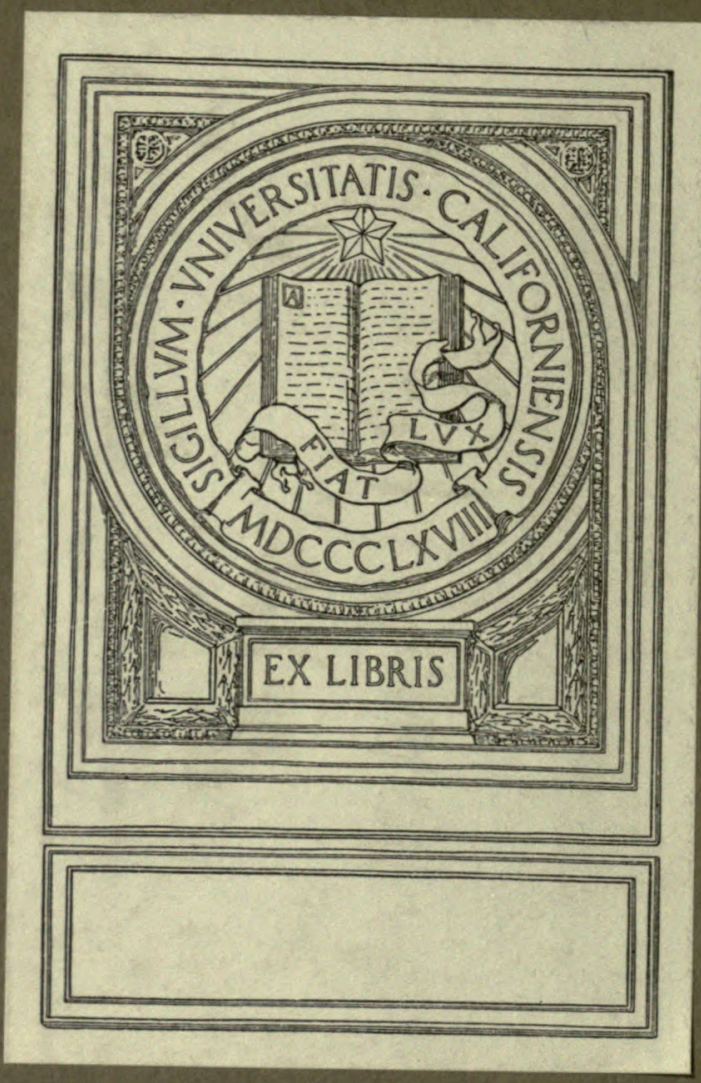




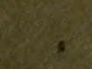


(1) 
SMITHSONIAN CONTRIBUTIONS TO KNOWLEDGE PART OF VOLUME XXXIV

\section{On the Construction of a Silvered Glass} Telescope, Fifteen and a Half Inches in Aperture, and its Use in Celestial Photography

BY HENRY DRAPER, M.D.

PROFESSOR OF NATURAL SCIENCE IN THE UNIVERSITY OF NEW YORK

(Reprinted from Vol, XIV, "Smithsonian Contributions to Knowledge," 1864)

AND

On the Modern Reflecting Telescope and the Making and Testing of Optical Mirrors

By GEORGE W. RITCHEY

ASSISTANT PROFESSOR OF PRACTICAL ASTRONOMY, AND SUPERINTENDENT OF INSTRUMENT CONSTRUCTION, IN YERKES OBSERVATORY

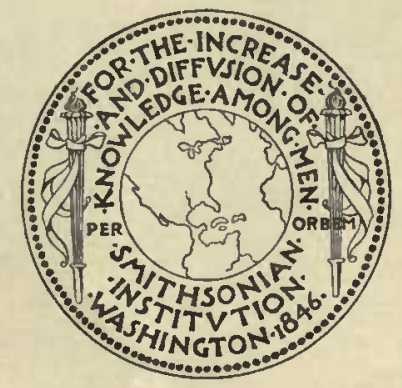

(No. 1459)

CITY OF WASHINGTON

PUBLISHED BY THE SMITHSONIAN INSTITUTION

1904 



\section{INTRODUCTION.}

For few papers published by the Institntion lias there been a more constant demand than for the memoir by Professor Henry Draper, entitled "On the Construction of a Silvered Glass Telescope," originally issued forty years ago, in 1864.

The paper is of remarkable merit as a summary of, and an addition to, the knowledge existing at the time, but during the long interval which has elapsed, progress has been made in various directions and by various hands.

On the occasion of a new edition of this classic memoir, it was sought to give an account of the latest knowledge on the subject, and I was gratified to be able to obtain from Mr. Ritchey, whose labors in this direction are so well known, an account of the processes which he has employed for making the great mirrors that have been so effective at the Yerkes Observatory, and it has been decided to re. publish, with the original Draper memoir, but as an entirely independent contribution to the subject, the present article by Mr. Ritchey.

The great refracting instruments which have beell produced in recent years have not superseded the use of the reflector, which, on the contrary, is occupying a more and more important place.

The reader is here presented with the most recent methods and results needed in the coustruction of great mirrors for modern reflecting telescopes.

S. P. Langley,

Washington, June, 1904. 



\section{ON THE CONSTRUCTION}

\section{SILVEREI) GLASS TELESCOPE,}

FIFTEEN AND A HALF INCHES IN APERTURE,

A N D

ITS USE IN CELESTIAL PHOTOGRAPHY.

BY

HENRY DRA PER, M. D.,

PROFESSOR OF NATURAL SCIENCE IN THE UNIVERSITY OF NEW YORK. 
C 0 M M IS S I 0 N

TO WHICH THIS PAPER HAS BEEN REFERRED.

Prof. Walcott GibBs.

Com. J. M. Gillies, U. S. N.

Joseph Henry,

Secretary S. 1 . 


\section{C $0 \mathrm{~N}$ T E N T S.}

HISTORICAL SKETCH OF THE TELWSCOPE. MEMOHR DIVIDED INTO SIX SECTIONS:-

§ 1. Girinding and Polishing the Mlirors . . . . . . . . . . . 2

1. Experiments on a metal speculum. Corrosion by aqua regia; voltaic grinding 2

2. Silvering glass. Foncault's and Cimeg's processes; details of silvering a mirror ; thiekness and durability of silver films ; their use in daguerreotyping * . . 2

3. Grinding and polishing glass. Division of subject . . . . . 6

a. P'eculiarities of glass; effects of pressure; effects of heat; oblique mirrors . 6

b. Emery and rouge; elutriation of emery . . . . . . . . . . I0

c. Tools of iron, lead, pitch ; the ganges; the leaden tool; the iron tool; the pitch polisher . . . . . . . . . 10

d. Methods of examination; two tests, eyepiece and opaque screen; appearance of spherical surface; oblate spheroidal surface; hyperbolic surface; irregular surface; details of tests; atmospheric movements; correction for parallel rays by measure; appearances in relief on mirrors . . . . . . . 13

e. Machines; Lord Rosse ; Mr. Lassell ; spiral stroke machine; its construction and use; the foot-power; method of local corrections; its advantages and disadvantages; machine for local corrections; description and use . . . 19

4. Eyepieces, plane mirrors, and test abjects _ . . . . . . . . . . 26

§ 2. The Telascope Mounting . . . . . . . . . . . . . . . . 27

Stationary eyepiece; method of counterpoising . . . . . . . . . 27

a. 'The tube; the mirrol' support; air sac; currents in the tube . . . 28

b. The supporting frame . . . . . . . . . . . . 31

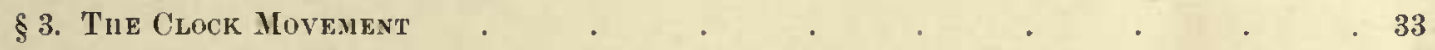

a. 'The sliding plateholder; the frietionless slide . . . . . . . 33

b. The clepsydra; the sand-clock . . . . . . . . $\quad 36$

c. The sun camera . . . . . . . . . . . . . 40

§4. The Observatory . . . . . . . . . . . . . . . . . . 41

a. The building . . . . . . . . . . . . . . 41

b. The dome; its peculiarities . . . . . . . . . . . 44

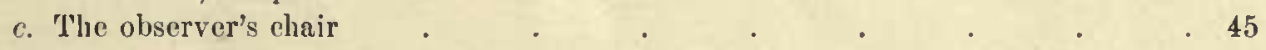

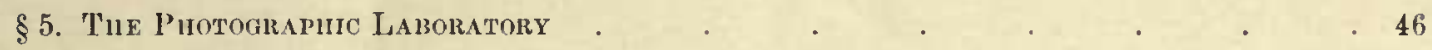

a leseription of the apartment . . . . . . . . . . . . 46

b. Ihotographic processes; washed plates; diffienlties of celestial photography . 47

§6. The Puotugraphic Enlarger . . . . . . . . . . . . . 5I

a. Iow powers; use of a concave mirror, its novelty and advantages; of the making of reverses . . . . . . . 5 I

b. High powers; microscopic photography . $\quad . \quad$. $\quad . \quad$. $\quad . \quad 54$ 



\section{A N A C C O U N T}

\section{THE CONSTRUCTION AND USE OF A SILVEREI) GLASS TELESCOPE.}

THE construction of a reflecting telescope capable of showing every celestial object now known, is not a very difficult task. It demands principally perseverance and careful observation of minutixe. 'The cost of materials is but trifling compared with the result obtained, and I can see no reason why silvered glass instruments should not come into general use among amateurs. 'The future hopes of Astronomy lie in the multitude of observers, and in the concentration of the action of many minds. If what is written here should aid in the advance of that noble study, I shall feel amply repaid for my labor.

A short historical sketeh of this telescope may not be uninteresting. In the summer of 1857, I visited Lord Rosse's great reflector, at Parsonstown, and, in addition to an inspection of the machincry for grinding and polishing, lad an opportunity of sceing several celestial objects through it. On returning home, in 1858, I determined to construct a similar, though smaller instrument; which, however, should be larger than any in America, and be especially adapted for photography. Accordingly, in September of that year, a 15 . inch speculum was cast, and a machine to work it made. In 1860 , the observatory was built, by the village carpenter, from my own designs, at my father's country scat, and the telescope with its metal specuhum mounted. This latter was, however, soon after abandoned, and silvered glass adopted. During 1861, the difficulties of grinding and polishing that are detailed in this account were met with, and the remedies for many of them ascertained. The experiments were conducted by the aid of three $15 \frac{1}{2}$ inch disks of glass, together with a varicty of smaller pieces. 'Three mirrors of the same focal length and aperture are almost essential, for it not infiequently happens that two in succession will be so similar, that a third is required for attempting an advance beyond them. One of these was made to acquire a parabolic figure, and bore a power of 1,000 . 'The winter was devoted to perfecting the art of silvering, and to the study of special photographic processes. A large portion of 1862 was spent with a regiment in a campaign in Virginia, and but few photographs were produced till autumin, when sand clocks and clepsydras of several kinds having been made, the driving mechanism attained great excellence. During the winter, the art of local corrections was acquired, and two $15 \frac{1}{2}$ inch mirrors, as well as two of 9 inches for the photographic enlarging apparatus, were completed. The greater part of 1863 has been occupied by lunar and planctary photography, and the enlargement of the small negatives obtained at the focus of the great reflector. Lunar negatives lave been produced which have been magnified to 3 feet in 
dianeter. I have also finished two mirrors $15 \frac{1}{2}$ inches in aperture, suitable for a Herschelian telescope, that is, which can only converge oblique pencils to a focus free from aberration. 'This work has all been accomplished in the intervils of professional labor.

The details of the preceding operations are arranged as follows: $\$ 1$. Grining and Polishing tue Mirrors; $\$ 2$. 'The Telescope Mounting; \$3. T'ine Chock Movement; $\$$ 4. 'The Onservatory; $\$ 5$. 'The Photographic Laboratory; $\$ 6$. The Photographic Enlarger.

\section{§1. GRINIING AND POLISHING TIIE MIRRORS.}

\section{(1.) Experiments on a Metal Speculum.}

My first 15 inch speculum was an alloy of copper and tin, in the proportions given by Lord Rosse. IIs general directions were closely followed, and the casting was very fine, free from pores, and of silvery whiteness. It was 2 inclies thick, weighed 110 pounds, and was intended to be of 12 feet focal length. 'The grinding and polishing were conducted with the Rosse machine. Althongh a great amount of time was spent in varions trials, extending over more than a year, a fine figure was never obtained-the principal obstacle to success being a tendency to polish in rings of different focal length. It must, lowever, be borne in mind that Lord Rosse had so thoronghly mastered the peculiarities of his machine as to produce with it the largest specula ever made and of very fine figure.

During these experiments there was occasion to grind ont some imperfections, $1 \frac{8}{10}$ of an inch deep, from the face of the netal. 'This operation was greatly assisted by stopping up the defects with a thick alcololic solution of Canada balsam, and having made a rim of wax around the edge of the mirror, pouring on nitro-hydrochloric acid, which quickly corroded away the uncovered spaces. Subsecpuently an increase in focal length of 15 inches was accomplished, by attacking the edge zones of the surface with the acid in gradnated depths.

An attempt also was marle to assist the tedions grinding operation by including the grinder and mirror in a Voltaic circuit, making the speculum the positive pole. By decomposing acidulated water between it and the grinder, and thereby oxidizing the tin and copper of the speculum, the operation was much facilitated, but the battery surface required was too great for common use. If a sufficient intensity was given to the current, speculum metal was transferred witlout oxidation to the grinder, and deposited in thin layers upon it. It was proposed at one tinte to make use of this fact, and coat a mirror of brass with a layer of speculum metal by electrotyping. 'I'he gain in lightuess would be considerable.

During the winter of 1860 the speculum was split into two pieces, by the expansion in freezing of a few drops of water that had found their way into the supporting case.

\section{(2) Silvering Glass.}

At Sir John Herschel's suggestion (given on the occasion of a visit that my father paid lim in 1860), experiments were next commenced with silvered glass 
specula. These were described as possessing great capabilities for astronomical purposes. 'They reflect more than 90 per cent. of the light that falls upon them, and only weigh one-eighth as much as specula of metal of equal aperture.

As no details of Steinheil's or Foucanlt's processes for silvering in the cold way were accessible at the time, trials extending at intervals over four montlis were made. A variety of reducing agents were used, and eventually good results obtained with milk sugar.

Soon after a description of the process resorted to by M. Foucault in his excellent experiments was procured. It consists in decomposing an alcoholic solution of ammonia and nitrate of silver by oil of cloves. The preparation of the solutions and putting them in a proper state of instability are very difficult, and the results by no means certain. The silver is apt to be soft and easily rubbed off, or of a leaden appearance. It is liable to become spotted from adherent particles of the solutions used in its preparation, and often when dissolved off a piece of glass with nitric acid leaves a reddish powder. Occasionally, however, the process gives excellent results.

In the winter of 1861 , M. Cimeg published his method of silvering lookingglasses by tartrate of potash and soda (Rochelle salt). Since I have made modifications in it fitting the silver for being polished on the reverse side, I have never on any occasion failed to secure bright, hard, and in every respect, perfect films.

'The operation, which in many details resembles that of M. Foucault, is divided into: 1st, cleaning the glass; 2d, preparing the solutions; $3 \mathrm{~d}$, warming the glass ; 4 th, immersion in the silver solution and stay there; 5th, polishing. It should be carried on in a room warmed to $70^{\circ} \mathrm{F}$. at least. The description is for a $15 \frac{1}{2}$ inch mirror.

1st. Clean the glass like a plate for collodion photography. Rub it thoroughly with nitric acid, and then wash it well in plenty of water, and set it on edge on filtering paper to dry. Then cover it with a mixture of alcohol and prepared chalk, and allow evaporation to take place. Rub it in suecession with many pieces of cotton flannel. This leaves the surface almost chemically clean. Lately, instead of chalk I lave used plain uniodized collodion, and polished with a freshly-washed picce of cotton flannel, as soon as the film had become semi-solid.

2l. Dissolve 560 grains of Rochelle salt in two or three ounces of water and filter. Dissolve 800 grains of nitrate of silver in four ounces of water. Take an ounce of strong ammonia of commerce, and add nitrate solution to it until a brown precipitate remains undissolved. Then add more ammonia and again nitrate of silver solution. This alternate addition is to be carefully continued until the silver solution is exhausted, when some of the brown precipitate should remain in suspension. The mixture then contains an undissolved excess of oxide of silver. Filter. Just before using, mix with the Rochelle salt solution, and add water enough to make 22 ounces.

The vessel in which the silvering is to be performed may be a circular dish (Fig. 1) of ordinary timplate, $16 \frac{1}{2}$ inches in diameter, with a flat bottom and perpendicnlar sides one inch high, and coated 
inside with a mixture of beeswax and rosin (equal parts). At opposite ends of one diameter two narrow pieces of wood, $\alpha a^{\prime}, \frac{1}{8}$ of an inch thick, are cemented. 'They are to keep the face of the mirror from the bottom of the vessel, and permit of a rocking motion being given to the glass. Before using such a vessel, it is necessary to touch any cracks that may have formed in the wax with a hot poker. A spirit lamp causes bubbles and holes through to the tin. 'The vessel too must always, especially if partly silvered, bo cleaned with nitric acicl and water, and left filled with cold water till needed. Instead of the above, India-rubber baths have been occasionally used.

3d. In order to secure fine and hard deposits in the shortest time and with weak solutions, it is desirable, though not necessary, to warm the glass shightly. 'This is best done by putting it in a tiub or other suitably sized vessel, and pouring in water enough to cover the glass. 'Then hot water is gradually stirred in, till the mixtme reaches $100^{\circ} \mathrm{F}$. It is also advantageons to place the vessels containing the ingredients for the silvering solntion in the same bath for a short time.

4th. On taking the glass out of the warm water, carry it to the silvering vesselinto which an assistant has just previously poured the mixed silvering solutionand immediately immerse it face dowwwards, dipping in first one edge and then quickly letting down the other till the face is horizontal. 'The back of course is not covered with the fluid. The same precautions are necessary to avoid strealis in silvering as in the case of putting a collodion plate in the bath. Place the whole apparatus before a window. Keep up a slow rocking motion of the glass, and watch for the appearance of the bright silver film. The solntion quickly turns brown, and the silver soon after appears, usually in from three to five mimntes. Leave the mirror in the liquid abont six times as long. At the expiration of the twenty minutes or half hom lift it ont, and look through it at some very bright object. If the object is scarcely visible, the silver surface must then be washed with plenty of water, and set on edge on bibulons paper to dry. If, on the contrary, it is too thin, put it quickly back, and leave it until thick enongh. When polished the silver onght, if held between the eye and the sme, to show his disk of a light bhe tint. On coming out of the bath the metallic surface shonld have a rosy goklen color by reflected light.

5th. When the mirror is thoronghly dry, and no drops of water remain about the edges, lay it upon its back on a thoronghly dusted table. 'Take a piece of the softest thin buckskin, and stuff it loosely with cotton to make a rubber. Aroid using the edge pieces of a skin, as they are always hard and contain nodules of lime.

Go gently over the whole silver surface with this rubber in circular strokes, in order to commence the removal of the rosy golden film, and to condense the silver. Then having put some very fine rouge on a piece of bnckskin laid flat on the table, impregnate the rubber with it. The best stroke for polishing is a motion in small eircles, at times going gradually round on the mirror, at times across on the various chords (Fig. 2). At the end of an hour of continnous gentle rubbing, with occasional touches on the flat. rouged skin, the surface will be polished so as to be perfectly black in oblique positions, and, with even moderate cure, scratchless. 
The process is like a burnishing. Put the rubber carefnlly away for another occasion.

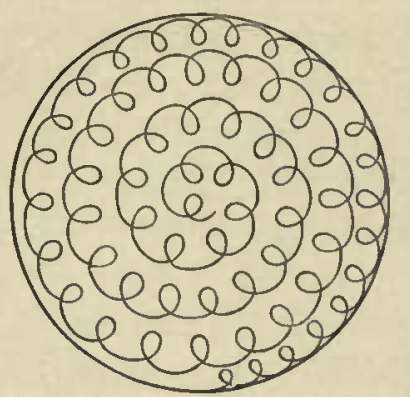

Fig. 2.

Polishing Strohes.

The thickness of the silver thus deposited is about $\frac{250,00 \overline{0}}{1}$ of an inch. Gold leaf, when equally transparent, is estimated at the same fraction. The actual value of the amount on a $15 \frac{1}{2}$ inch mirror is not quite a cent - the weight being less than 4 grains (239 milligrammes on one occasion when the silver was nnusually thick), if the directions above given are followed.

Variations in thickness of this film of silver on varions parts of the face of the mirror are consequently only small fractions of $\frac{1}{20} \overline{0}, 0 \overline{0}$ of an inch, and are therefore of no optical moment whatever. If a glass has been properly silvered, and shows the sum of the same color and intensity through all parts of its surface, the most delicate optical tests will certainly fuil to indicate any difference in fignre between the silver and the glass underneath. The faintest peculiarities of local surface secn on the glass by the method of M. Foncault, will be reproduced on the silver.

The durability of these silver films varies, depending on the circumstanees under which they are placed, and the method of preparation. Snlphuretted hydrogen tarnishes them quickly. Drops of water may split the silver off. Under certain ciremmstances, too, minute fissmes will spread all over the surface of the silver, and it will apparently lose its adhesion to the glass. 'This phenomenon seems to be commeted with a continued exposure to dampness, and is aroided by grimding the edge of the concave mirror flat, and keeping it covered when not in use with a sheet of flat plate gliss. IIcat seems to have no prejudicial effect, though it might have been supposed that the difference in expansibility would have overcome the mutnal arlhesion.

Generally silvered mirrors are very endming, and will bear polishing repentedly, if previously dried by heat. I have some which have been used as cliagonal reflectors in the Newtonian, and have been exposed during a large part of the day to the heat of the sun concentrated by the $15 \frac{1}{2}$ inch mirror. 'These small mirrors are never covered, and yet the one now in the teleseope has been there a year, and has had the dusty film-like that which acenmulates on glass-polished off it a dozen times.

In order to guard against tamishing, experiments were at first male in gilding silver films, but were abundoned when found to be mnecessary. A partial conversion of the silver film into a golden one, when it will resist sulphuretted lyydrogen, 
can be accomplished as follows: Take three grains of hyposulphite of soda, and dissolve it in an ounce of water. Add to it slowly a solution in water of one grain of chloride of gold. A lemon yellow liquicl results, which eventually becomes clear. Immerse the silvered glass in it for twenty-four hours. An exchange will take place, and the film become yellowish. I lave a piece of glass prepared in this way which remains unlunt in a box, where other pieces of plain silvered glass have changed some to yellow, some to blue, from exposure to coal gas.

I have also used silvered glass plates for dagnerreotyping. They iodize beantifully if freshly polished, and owing probably to the absence of the usual copper alloy of silver plating, take impressions with very short exposures. The resulting pieture has a rosy warnth, rarely seen in ordinary daguerreotypes. The only precantion necessary is in fixing to nse an alcoholic solution of cyanide of potassium, instead of lyposulphite of soda dissolved in water. 'The latter las a tendency to split up the silver. 'llhe subsequent washing must be with diluted common alcohol.

Pictures obtained by this method will bear high magnifying powers without showing granulation. Unfortunately the exposure required for them in the telescope is six times as great as for a sensitive wet collodion, thougl the iodizing be carried to a lemon yellow, the bromizing to a rose red, and the plate be returned to the iocline.

\section{(3.) Grinding and Polishing Glass.}

Some of the facts stated in the following paragraphs, the result of numerous experiments, may not be new to practical opticians. I lave had, however, to polish with my owu hands more than a lumelred mirrors of various sizes, from 19 inches to $\frac{1}{4}$ of an inch in diameter, and to experience very frequent failures for three years, before succeeding in producing large surfaces with certainty and quickly. It is well nigh impossible to obtain from opticians the practical minutio which are essential, and which they conecal even from each other. The long continued researches of Lord Rosse, Mr. Lassell, and M. Foncault are full of the most valuable facts, and have been of continual use.

The subject is divided into: a. The Peculinities of Glass; b. Emery and Rouge: c. 'Tools of Iron, Lead and Pitch; d. Methods of Examining Surfaces; e. Machines.

\section{a. Peculiarities of Glass.}

Effects of Pressure.--It is generally supposed that glass is possessed of the power of resistance to compression and rigidity in a very marked manner. In the course of these experiments it has appeared that a sheet of it, even when very thick, can with difficulty be set on elge without bending so much as to be optically worthless. Fortumately in every disk of glass that I have tried, there is one diameter on either end of which it may stand without liarm.

In examining lately various works on astronomy and optics, it appears that the same difficulty has been found not only in glass but also in speculum metal. Short used always to mark on the edge of the large mirrors of lis Gregorian telescopes the point which should be placed uppermost, in case they were removed from their cells. In achromatics the image is rery sensibly clanged in sharpuess if the flint 
and crown are not in the best positions; and Mr. Airy, in mounting the Northumberland telescope, had to arrange the means for turning the lenses on their common axis, until the finest image was attained. In no accomnt, however, have I found a critical statement of the exact nature of the deformation, the observers merely remarking that in some positions of the object glass there was a sharper image than in others.

Before I appreciated the facts now to be mentioned, many fine mirrors were condemned to be re-polished, which, had they been properly set in their mountings, wonld have operated excellently.

In attempting to ascertain the nature of deformations by pressure, many changes were macke in the position of the disk of glass, and in the kind of support. Some square mirrors, too, were ground and polished. As an example of the final results, the following case is presented: A $15 \frac{1}{2}$ inch unsilvered mirror $1 \frac{1}{4}$ inch thick was set with its best diameter perpendienlar, the axis of the mirror being horizontal (Fig. 8). The image of a pin-liole illuminated by a lamp was then observed to be single, sharply defined, and with interference rings surrounding it as at $a$, Fig. 3. On turning the glass 90 degrees, that is oue quarter way round, its axis still pointing in the same direction, it conld hardly be realized that the sane concave surface was converging the rays. The image was separated into two of about equal intensity, as at $b$, with a wing of light going ont above and below from the junction. Inside and outsicle of the focal plane the cone of rays had an elliptical section, the major axis being horizontal inside, and perpendicular outside. 'Tuming the mirror still Fig. 3.

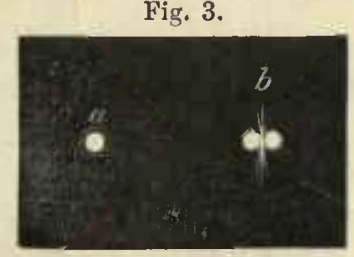

Effect of Pressure on a Reflecting Surface. more round the inage gradually improved, until the original diameter was perpendicular again-the end that had been the nppermost now being the lowest. A similar series of changes occurred in supporting the glass on various parts of the other semicircle. It might be supposed that irregularities on the edge of the glass disk, or in the supporting are would account for the phenomena. But two facts dispose of the former of these liypotheses: in the first place if the glass be turned exactly half way round, the character of the image is unchanged, and it is not to be believed that in many different mirrors this conld occur by chance coincidence. In the secoud place, one of these mirrors has been earefully examined after being ground and polished three times in succession, and on each occasion required the same riameter to be perpendicular. As to the second hypothesis no material difference is observed whether the supporting are below be large or small, wor when it is replaced by a thin semicircle of timplate lined with cotton wool.

I an led to believe that this peculiarity results from the structural arrangement of the glass. 'The specimens that have served for these experiments have probably been snbjected to a rolling operation when in a plastic state, in order to be reduced to a uniform thickness. Optical glass, which may be made by softening down irregular fragments into moulds at a temperature below that of fusion, may have the same difficnlty, but whether it has a dianeter of minimum compression can only be determined by experiment. Why speculum metal should have the same property might be ascertained by a critical cxamination of the process of casting, 
and the effect of the position of the openings in the monld for the entrance of the molten metal.

Effects of Heut.--The preceding chimges in glass when isolated appear very simple, and their remedy, to keep the proper diameter perpendicular, is so obvious that it may seem surprising that they should have given origin to any cmbarrassment. In fact it is now desirable to have a disk in which they are well marked. But in practice they are complicated in the most trying manner with variations produced by heat pervading the various parts of the glass unequally. The following ease illustrates the effects of heat:-

A $15 \frac{1}{2}$ inch mirror, which was giving at its centre of curvature a very fine image (a, Fig. 4) of an illuminated pin-hole, was heated at the edge by placing the right

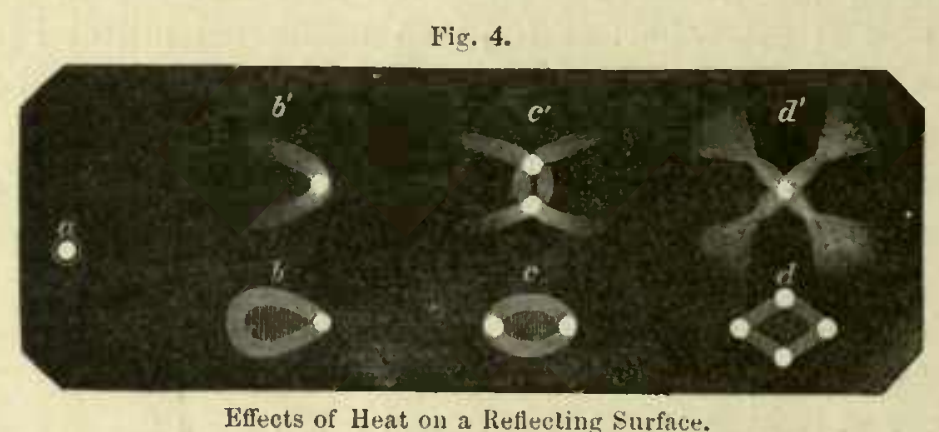

hand on the back of the mirror, at one end of the horizontal diameter. In a few seconds an are of light came out from the image as at $b^{\prime}$, and on putting the left liand on the other extremity of the same diameter the appearance $c^{\prime}$ was that of two ares of light crossing each other, and having an image at cach interscetion. 'The mirror did not recover its original condition in ten minutes. Another person on a subsequent occasion touching the ends of the perpendicular diameter at the same time that the horizontal were warmed, caused the image $d^{\prime}$ to become somewhat like two of $c^{\prime}$, put at right angles to each other. A little distance outside the focus the complementary appearances, $b, c, d$, were found.

By unsymmetrical warming still nore remarkable forms emerged in suecession, some of which were more like certain nebula with their milky light, than any regular geometrical figure.

If the glass had, after one of these experiments, been immediately put on the

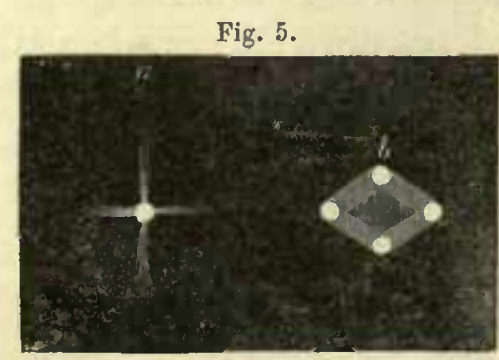

Effects of Heat rendered permanent. polishing machine and re-polished, the changes in surface would to a certain extent have become permanent, as in Chinese specula, and the mirror would have required either re-grinding or prolonged polishing to get rid of them. 'This occurred unfortmutely very frequently in the earlier stages of this series of (xperiinents, and gave origin on one.occasion to a surface which conld only show the image of a pin-hole as a lozenge (b, Fig. 5), with an image at cach angle inside the focus, and as an image $a$ with four wings outside

But it must not be supposed that such apparent causes as these are required to 
disturb a surface injuriously. Frequently mirrors in the process for conrection of spherical aberration will change the quality of their images without any perceptible reason for the alteration. A current of cold or warm air, al gleam of sumlight, the close approach of some person, an myguarded touch, the application of cold water injudiciously will ruin the labor of days. The avoidance of these and similar canses requires personal experience, and the amateur can only be advised to use too much caution ratler than too little.

Such accidents, too, teach a useful lesson in the management of a large telescope, never, for instance, to leave one-half the mirror or lens exposed to radiate into cold space, while the other half is covered by a comparatively warm dome. Under the head of the Sun-Camera, some further facts of this kind may be found.

Oblique Mirrors.-Still another propensity of glass and specnlum metal must be noted. A truly spherical concave can only give an image free from distortion when it is so set that its optical axis points to the object and returns the image directly back towards it. But I have polished a large number of mirrors in which an inage free from distortion was prodneed omly when oblique pencils fell on the mirror, and the image was retumed along a line forming an angle of from 2 to 3 degrees with the direction of the object. Such mirrors, thongh exactly suited for the Herschelian construction, will not officiate in a Newtonian unless the diagonal mirror be put enough out of eentre in the tube, to compensate for the figure of the mirror. Some of the best photographs of the moon that have been produced in the observatory, were made when the diagonal mirror was 6 inches out of centre in the 16 inch tube. Of course the large mirror below was not perpendicular to the axis of the tube, but was inclined $2^{\circ} 32^{\prime}$. 'The figure of such a concave might be explained by the supposition that it was as if cut out of a parabolic surface of twice the diameter, so that the vertex should be on the edge. But if the mirror was turned $180^{\circ}$ it apparently did just as well as in the first position, the image of a round object being neither oval nor elliptical, and without wings. The image, however, is never quite as fine as in the usual lind of mirrors. 'The true explanation seems rather to be that the radius of curvature is greater along one of the diameters than along that at right angles. How it is possible for such a figure to arise during grinding and polishing is not easy to mulerstand, unless it be granted that glass yields more to heat and compression in one direction than another.

After these facts had been laboriously ascertained, and the method of using such othervise valueless mirrors put in practice as above stated, chance brought a letter of Maskelyne to my notice. He siys, "I hit upon an extraordinary experiment which greatly improved the performance of the six-fect reflector" . . . . . It was one made by Short. "As a like management may improve many other telescopes, I shall here relate it: I removed the great spcculum from the position it ought to hold perpendicular to the axis of the tube when the telescope is said to be rightly adjusted, to one a little inclined to the same and found a certain inclination of abont $2 \frac{10}{2}$ (as I found by tlic alteration of objects in the finer one of 1'ollond's best night glasses with a field of $6^{\circ}$ ), which cansed the teleseope to show the object (a printed paper) incomparably better than before; insomuch that I could read many of the words which before I could make nothing at all of. It is plain, therefore, that this 
telescope shows best with a certain oblique pencil of rays. Probably it will be found that this circumstance is by no means peculiar to this telescope." This very valuable obscrvation has lain buried for eighty-two years, and ignorance of it has led to the destruction of many a valuable surface.

As regards the method of combating this tendeney, it is as a general rule best to re-grind or rather re-fine the surfuce, for though pitch polishing has oceasionally corrected it in a few minutes, it will not always do so. 1 have polished a surface for thirteen and a half hours, examining it frequently, without changing the obliquity in the slightest degree.

Glass, then, is a substance prone to change by heat and compression, and requiring to be handled with the utmost caution.

\section{b. Emery and Rouge.}

In order to excavate the concave depression in a piece of glass, emery as coarse as the head of a pin lias been commonly used. This cuts rapidly, and is sueceederl by finer grained varieties, till flour emery is reached. After that only washed emeries should be permitted. They are made by an elutriating process invented by Dr. Green.

Five pounds of the finest sifted flour enery are mixed with an ounce of pulverized gum arabic. Enough water to make the mass like treacle is then added, and the ingredients are thoroughly incorporated by the hand. They are put into a decp jar containing a gallon of water. After being stirred the fluid is allowed to come to rest, and the surface is skimmed. At the end of an hour the liquid containing extremely fine emery in suspension is decanted or drawn off with a siphon, nearly down to the level of the precipitated emery at the bottom, and set aside to subside in a tall vessel. When this has occurred, which will be in the lapse of a few hours, the fluid is to be carefully poured back into the first vessel, and the fine deposit in the second put into a stoppered bottle. In the same way by stirring up the precipitate again, encry that has been suspended 30,10,3,1 minutes, and 20,3, seconds is to be sccured and preserved in wirle-mouthed vessels.

The quantity of the fincremeries consumed in smoothing a $15 \frac{1}{2}$ inch surface is very trifling - a mass of each as large as two peas sufficing.

Rouge, or peroxide of iron, is better bonght than prepared by the amatem. It is made by calcining sulphate of iron and washing the product in water. Three kinds are usually found in commerce: a very coarse variety containing the largest percentage of the cutting black oxide of iron, which will scratch glass like quartz; a very fine variety which can hardly polish glass, but is suitable for silver films; and one intermediate. Trial of several boxes is the best method of procuring that which is desired.

\section{c. Tools of Iron, Lead, and Pitch.}

In making a mirror, one of the first steps is to describe upon two stont sheets of brass or iron, ares of a circle with a radius equal to twice the desired focal length, and to secure, by filing and grinding them together, a concave and convex gauge. When the radius bar is very long, it may be hung against the side of a loouse. By 
the assistance of these templets, the convex tools of lead and iron and the concave surface of the mirror are made parts of a sphere of proper diameter.

The exeavation of a large flat dise of glass to a concave is best accomplished by means of a thick plate of lead, cast considerably more convex than the gauge. 'The central parts wear away very quickly, and when they become too flat must be made convex again by striking the lead on the back with a hammer. The glass is thus cansed gradually to approach the right concavity. 'Ten or twelve hours usually suffice to complete this stage. The progress of the excavating is tested sufficiently well by setting the convex gange on a dianeter of the mirror, and observing how many slips of paper of a definite thickness will pass under the centre or edge, as the case mily be. 'This aroids the necessity of a splierometer. The thickness of paper is found correctly enough by measuring a half ream, and dividing by the number of sheets. In this manner differences in the versed sine of a thousandth of an inch may be appreciated, and a close enough approximation to the desired focal length reached--the precision required in achromatics not being needed. The preparation of the iron tools on which the grinding is to be finished is very laborious where personal exertion is used. They require to be cast thin in order that they may be easily handled, and hence cannot be turned with very great exactness.

The pair for my large mirrors are $15 \frac{1}{2}$ inches in diameter, and were cast $\frac{3}{8}$ of an inch thick, being strengthened however on the back by eight ribs $\frac{3}{4}$ of an inch high, radiating from a solid centre two inches in diameter ( $a$, Fig. 6). They weighed 25

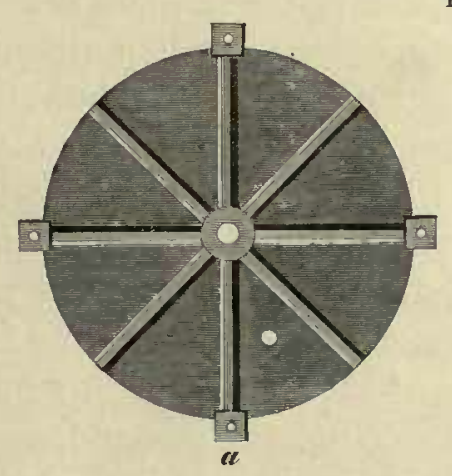

Fig. 6.

The Iron Grinder.

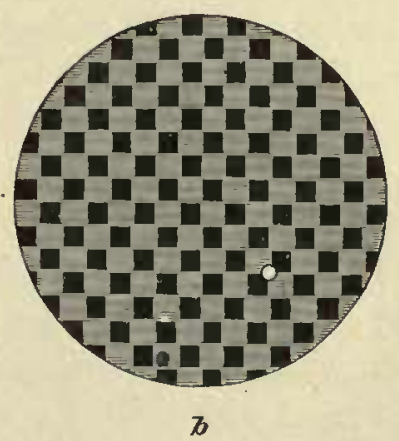

pounds apiece. Four ears, with a tapped hole in each, project at equal distances round the erge, and serve eitlier as a means of attacliment for a counterpoise lever, or as handles.

After these were turned and taken off the lathe chuck, they were found to be somewhat sprung, and had to be scraped and ground in the machine for a week hefore fitting properly. 'The slowness in grinding results from the emery becoming imbedded in the iron, and forming a surfice as hard as adamant.

Once acquired, such grinders are very valuable, as they keep their focal length and figure apparently without change if carefully used, and only worked on glass of nearly similar curvature. At first no grooves were cut upon the face, for in the 
lead previously employed for fining they were found to be a fruitful source of scratches, on account of grains of emery imbedding in them, and gradually breaking loose as the lead wore away. Subsequently it appeared, that unless there was some means of spreading water and the grinding powders evenly, rings were likely to be produced on the mirror, and the iron was consequently treated as follows:-

A number of pieces of wax, such as is used in making artificial flowers, were procured. 'The convex iron was laid out in squares of $\frac{3}{4}$ of an incle on the side, and each alternate one being touched with a thick alcoholic solution of Canada balsam, a piece of wax of that size was put over it. 'This was found after many trials to be the best method of protecting some squares, and yet leaving others in the most suitable condition to be attacked. A rim of wax, melted with Canada balsan, was raised around the edge of the iron, and a pint of aqua regia poured in. In a slort time this corroded out the uncovered parts to a sufficient depth, leaving an appearance like a chess-board, except that the projecting squares dich not touch at the adjoining angles (b, Fig. 6). I should have chipped the cavities ont, instead of dissolving them away, but for fear of changing the radius of curvature and breaking the thin plate. However as soon as the iron was cleaned, it proved to have become flatter, the radius of eurvature having increased $7 \cdot \frac{3}{1}$ inches. 'This shows what a state of tension and compression there must be in such a mass, when the removal of a film of metal $\frac{1}{50}$ of an inch thick, here and there, from one surface, causes so great a change.

When the glass has been brought to the finest possible grain on such a grinder, a polishing tool lias to be prepared by covering the convex iron with either pitch or rosin. 'These substances have very similar properties, but the rosin by being clear affords an opportunity of seeing whether there are impurities, and therefore has been frequently used, straining being umecessary. It is, however, too hard as it oecurs in commeree, and requires to be softened with turpentine.

A mass sufficiently large to cover the iron $\frac{1}{8}$ of an inch thick is melted in a porcelain or metal capsule by a spirit lamp. When thoronghly liquid the lamp is blown ont, and spirits of turpentine added, a drachm or two at a time. After each addition a chisel or some similar piece of metal is dipped into the fluid rosin, and then immersed in water at the temperature of the room. After a minute or two it is taken out, and tried with the thumb-nail. When the proper degree of softness is

Fig. 7.

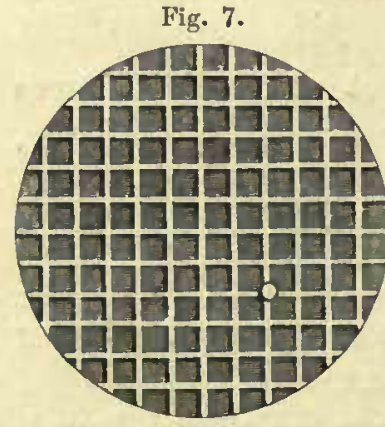

The Polishing Tool. obtained, an indentation can be made by a moderate pressure.

'The iron having been heated in hot water is then painted in stripes $\frac{1}{8}$ of an inch decp with this resinous composition. The glass concave to be polished being smeared with ronge, is pressed upon it to secure a fit, and the iron is then jut in cold water. With a narrow ehisel straight grooves are made, dividing the surface into squares of one inch, separated by intervals of one-quarter of an inch (Fig. 7). Under certain circumstances it is also desirable to take off every other square, or perhaps reduce the polishing surface irregularly here and there, to get an excess of action on some particular portion of the mirror. 
It is well, on commeneing to polish with a tool made in this way, to warm the glass as well as the tool in water (page 4) before bringing the two in contact. If this is not done the polishing will not go on kindly, a good adaptation not being secured for a length of time, and the glass surface bcing injured at the ontset. The rosin on a polisher put away for a day or two suffers an internal change, a speeies of irregular swelling, and does not retain its original form. Heating, too, has a good effect in preventing disturbance by local variations of temperature in the glass.

'The description of "Local Polishers" will be given under Machines.

\section{d. Methods of Examining Surfuces.}

I have been in the habit of testing mirrors cxclusively at the centre of curvature, not putting them in the telescope tube until nearly parabolic or finished. The means of trial are so excellent, the inclications obtained so precise, and the freedom from atmospheric disturbances so complete, that the greatest facilities are offered for ascertaining the nature of a surface. In addition the observer is entirely independent of day or night, and of the weather. I do not think that anything more is learned of the telescope, even muler favorable circunstances, than in the workshop. For the improvement of these methols of observation, Science is largely indebted to M. Foucault, whose third test--the second in the next paragraph-is sufficient to afford by itself a large part of the information required in correcting a concave surfice.

There are two distinct moles of examination: 1st, observing with an eye-piece the image of an illuminated pin-hole at the focus, and the cone of rays insicle and outside that plane; $2 \mathrm{~d}$, receiving the entire pencil of light coming from the mirror through the pupil on the retina, and noticing the distribution of light and shade, and the appearances in relief on the face of the mirror.

The arrangements for these tests are as follows: Around the flame of a lamp $(u$,

Fig. 8.

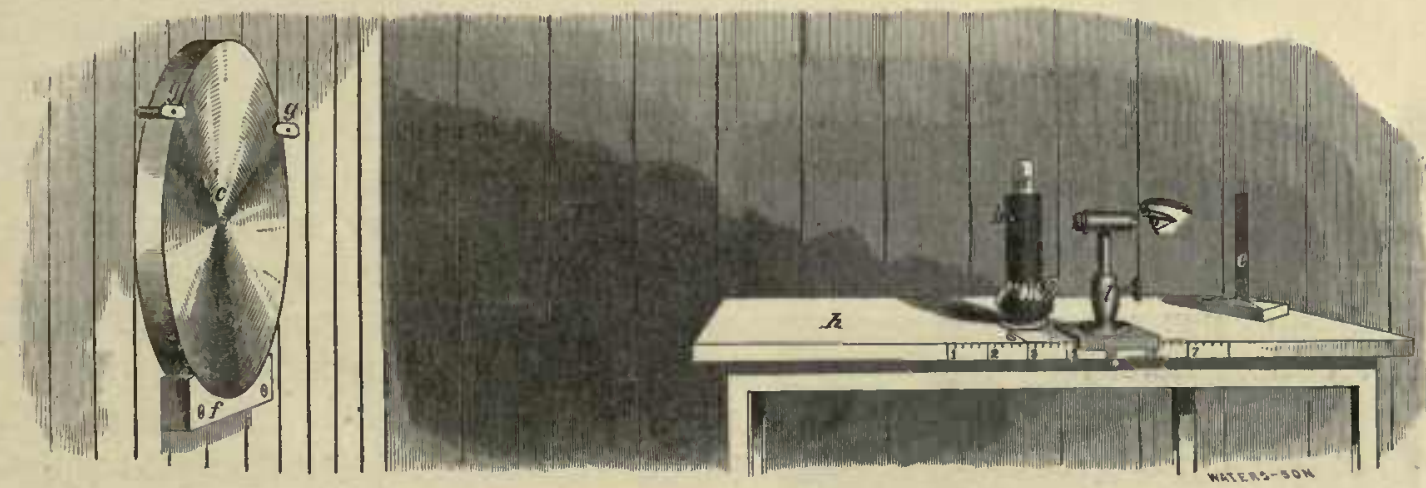

Testing a Concave at the Centre of Curvature.

Fig. 8) a sheet of tin is bent so as to form a eylindrieal sereen. Through it at the height of the briglitest part of the flame, as at $b$, two holes are bored, a quarter of an inch apart, one $\frac{1}{3}$ of an inch in cliameter, the other as small as the point of the finest neclle will make-perhaps $\frac{1}{200}$ of an inch. This apparatus is to be set at the centre 
of curvature of the mirror $c$-the optical axis of the latter being horizontal-and so adjusted that the light which diverges from the illuminated hole in use, may, after impinging on the concave surface of the glass, return to form an inage close by the side of the tin screen. In the case of the first test, the retuming rays are received into an eye-piece or microscope, $d$, magnifying 20 times, and moving upon a divided scale to and from the mirror. In the second test the eye-piece is removed away from before the eye, and a straight-edged opaque sereen, $e$, is put in its place. The mirror is supported in these trials by an are of wood $f$, lined with thick woollen stuff, and above two wooden latches, $g, y$, prevent it from from falling forward, but do not compress it. It is, of course, unsilvered. In the figure the table is represented very much closer to the mirror than it should be. In trials on the $15 \frac{1}{2}$ inch it has to be 25 feet clistant.

The appearance that al truly spherical concave surface presents with the first test is: the image of the hole is sharply defined without any areola of aberration around it, and is surrounded by interference rings. Inside and outside the focus the cone of rays is exactly sinilar, and cireular in section. It presents no trace of irreginar illumination, nor any bright or dark circles. With the second test, when the eye is brought into such a position that it receives the whole pencil of reflected rays, and the opaque screen is gradually drawn across in front of the pupil, the brightness of the surface slowly diminishes, until just as the screen is cutting off the last

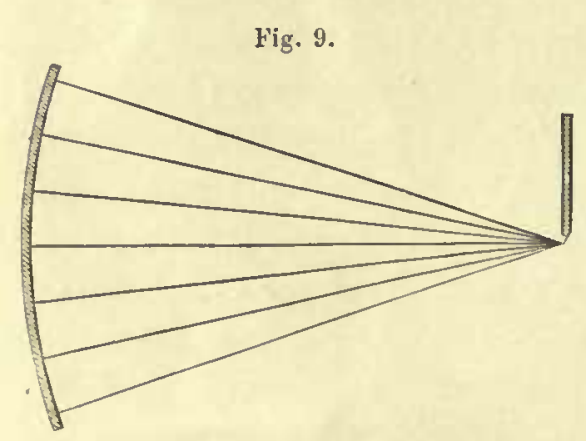

Action of the Opaque Screen. relic of the cone of rays (Fig. 9), the mirror presents an uniform grayish tint, followed by total darkness, and gives to the eye the sensation of a plane.

If, however, the mirror is not spherical, but instearl gradually decreases in focal length towaril the elge, the following changes result: 'The image at the best focus is surromeler by a nebulosity, stronger as the deviation from the sphere is greater, and neither ean a sharp focus be obtained nor interference fringes scen. In order to include this nebulosity in the image, it will be necessary to push the eye-piece toward the mirror. Before the cone of rays has conpleted its convergence, the mass of light will be seen to have accumulated at the periphery, and after the focus

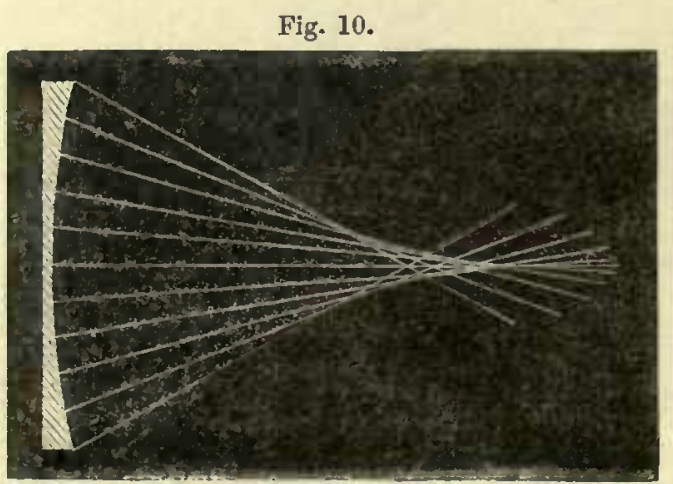

Caustic of Oblate Spheroidal Mirror. is past and divergence has commenced, the accumulation will be around the axis. 'That is, a caustic (Fig. 10) is formed with its summit from the mirror. By the second test, in gradually eclipsing the light coming from the mirror, just before all the rays are obstructed, a part of those which have constituted the nebulosity will escape past the screen (Fig. 11) into the eye, and cause there an extremely exaggerated appearanes in relief of the solid superposed upon the 
true surface beneatli. 'The glass will no longer seem to be a plane, but to have a section as in Fig. 12. Let us examine by the aid of M. Foucanlt's diagrams why it is that the surface seems thus curved. If the dotted line, Fig. 13, represents the section of the mirror, and the solid line a section of a splicrical mirror of the same mean focal length, it will be seen that the curves touch at two points, but are separated by an interval elsewhere. If this interval be projected by means of the differences of the ordinates,

Fig. 12.

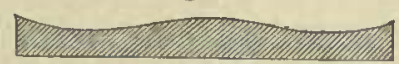

Apparent Section of Oblate SpleroidaI Mirror.

the resulting curve will be found to be the same as that which the nirror apparently has.

If the opaque screen be drawn a short distance from the mirror, the appearance of the section curve will seem to change, the bottom of the groove (Fig. 12) between the centre and edge advancing inwards, and the mound in the middle growing smaller. If the screen be pushed toward the mirror the reverse takes place, the contral mound becoming larger, but the edge decreasing. 'The reason for these variations becomes apparent by considering the three diagrams, Fig. 14. 'The dotted curve in each instance represents the real curve of the mirror described in the last paragraph, while the solid lines are circles drawn with radii progressionally shorter in $a, b$ and $c$, and represent sections of three spherical mirrors whose focal lengthis also progressively shorten.

When the opaque screen is at a given distance from the mirror under examination, the only parts of the mirror which can officiate well are those which have a curvature corresponding to a radius equal to the same

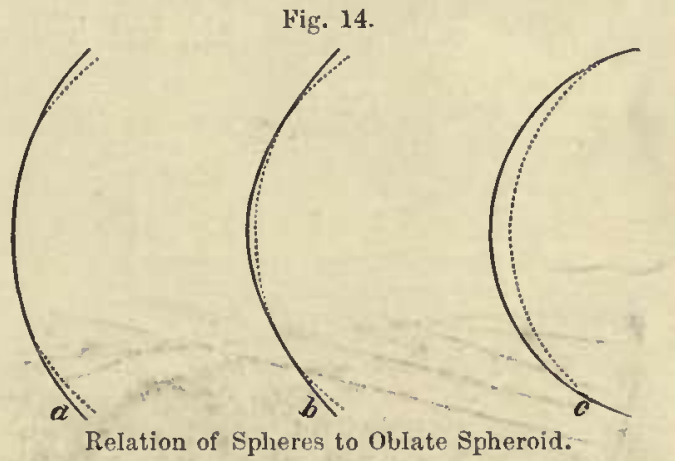

distance. All the other parts seem as if they were covered by projecting circular masses. In looking at Fig. 14, it is plain, then, if the opaque screen is at a maximum distance from the mirror, that the central parts alone will seem to operate, because the two curves $(a)$ only touch there. If the screcn is moved toward the mirror the curves (b) will coincide at some point between the centre and edge, while if carried still farther in only the edges toucls and the appearance will be as if a 
large mound were fixed upon the centre. I have been cureful in explaining how a surface may thus seem to present entirely different characteristics if exanined from points of view which vary slightly in distance, becanse a knowledge of these facts is of the utmost importance in correcting such an erroneous figure. It is now obvious that the correction will be equally effectual if the mirror be polished with it small rubber on the edge, or on the centre, or partly on each. 'The only difference in the resnlt will be, that the mean focal length will be increased in the first instance, and decreased in the second, while it will remain unchanged in the third.

If the mirror, instead of having a section like that of an oblate spheroir, should have either an ellipse, parabola, or hyperbola, as its section curve, the appearances seen above are reversed. Whilst by the first test there is still an aberration round the iniage at the best focus, the eye-piece must now be drawn from the mirror to include it. The cone of rays is most dense round the axis inside, and at the

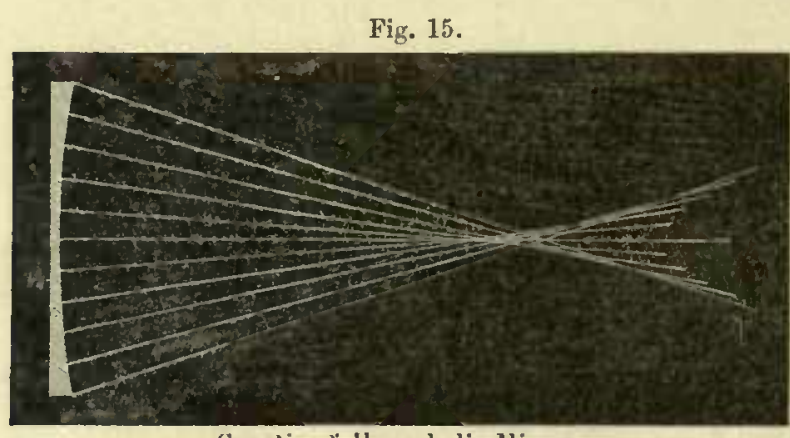

Caustic ol Hyperbolic Mlirror.

Fig. 16.

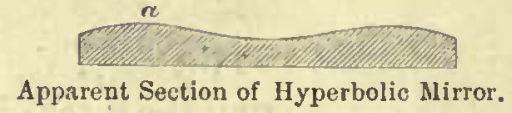
periphery ontside the focus, and the summit of the caustic (Fig. 15) is turned towards the mirror. The second test shows a section as in Fig. 16, a depression at the centre, and the edges turned backwards. The nature of the movement necessary to reduce the surfice to a sphere is very plainly indicated, action on a zone $a$ between the centre and edge. If, however, a parabolic section is required, the \%one a must not be entirely removed, ind the surface rendered apparently flat, but as much

of it must be left as experience shows to be desirable.

If, in still a fourth instance, the mirror is not formed by the revolution of any regular curve upoil its axis, but has upon its surfuce zones of longer and shorter

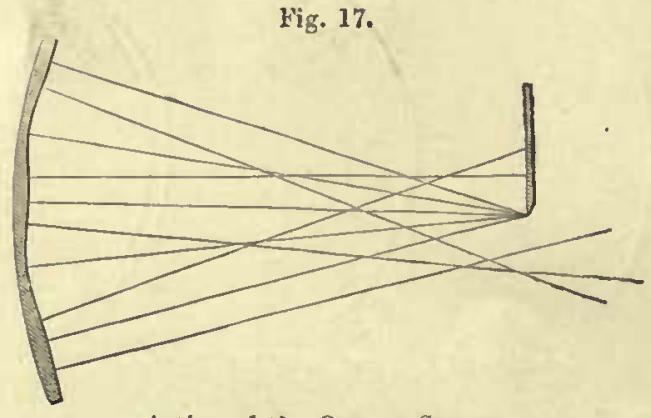

Action of the Opaque Screen.

Fig. 18.

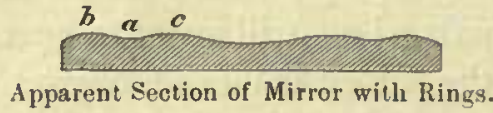

radius intermixed irregularly, a very common case, the two tests still indicate with precision the parts in fault, and the correction demanded. 'Thus the mirror seen in section in Fig. 17, when the principal miss of light was obstructed by the opaque screen, would still pernit that coming from certain parts to find its way into the eye.

Figure 18 represents an irregular mirror, that was produced in the process of correction of a hyperbolic surface, which had an apparent section like Fig. 16 previously. 'The zone a had been acted upon with a small local polisher, and the mirror was

finished by subsequently softening down $b$ and $c$ with a larger tool. 
After having gained from the preceding paragraphs a general idea of the value and nature of these tests at the centre of curvature, a more particular description of their use is desirable. M. Foncault in his methorls first lings the mirror to a spherical surface, and then by moving the luminous pin-hole towart the mirror, and correspondingly retracting the eye-piece or opaque screen, carries it, aroiding aberration continually by polishing, through a series of ellipsoidal curvatures, ardvancing step by step toward the paraboloid of revolution. The length of the apartment, however, soon puts a termination to this gradual system of correction, and he is foreed to perform the last steps of the conversion by an empirical process, and eventually to resort to trial in the telescope.

With my mirrors of 150 inches focal length, demanding from the outset a room more than 25 fect long, this successive system harl to be alhandonerl. It was not founcl feasible to place the lamp in the distant focus of the ellipse-the workshop being less thin 30 feet long-and putting the luminous source on stands outside, introduced several injurions complications, not the least of which was currents in the layers of viriously refracting air in the apartment.: In a still room the density and hygrometric variations in its varions parts only give rise to slight enibarrassment. 'The moment, however, that currents are produced, satisfactory examination of a mirror becomes difficult. 'The air is seen only too ensily to move in great spiral convolutions between the mirror and the eye, areolic of aberration appear aronnd a previously excellent image, and were it not for the second test, any retermination of surface would be impossible. : By that test the real deviations from truth of figure can be distinguished from the atmospheric, and to a practised eye sufficient indications of necessary changes given. Such a movement as that eaused by placing the liand in or under the line of the converging rays, will completely destroy the beauty of an image, and by the second test give origin in the first cuse to the appearance lig. 19. In order to be completely exempt at all times from aërial difficulties, it is desirable to have control of a long unrlerground apartment, the openings of which can be tightly closed. As no artificial warmth is neederl, there is the minimum of movement in the

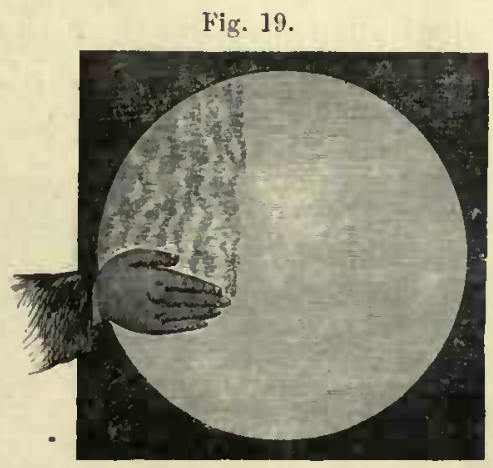

Atmospheric Molions. inclosed air, and conclusions respecting a surfice may be arriver at in a very short time. 'The mirror may also be supported from the ground, so that tremulous vibrations which weiry the eye, and interfere with the accuracy of criticism, maly be avoirded.

Driven then from observing an image kept contimually frec from aberration, through andvancing ellipsoidal changes, it became necessiry to study the gradual increase of deformation, produced by the greater and greater departures from a sphericul surface, as the parabola was approached. It was found that a sufficient gruide is still provided in these tests, by modifying them properly.

'The longitudinal aberration of a mirror of small angular opening is easily calculated-being equal to the square of half the aperture, divided by eight times the

3 June, 1864. 
principal focal length. That is, if a $15 \frac{1}{2}$ inch mirror of 150 inches focal length were spherical, and were used to converge parallel rays, those from its elge would reach a focus $\bar{i} \frac{5}{4} \overline{0}$ of an inch nearer, the mirror than those from its eentral parts. If now the converse experiment be tried, and a mirror of the same size and focal length which can converge parallel rays, falling on all its parts, to one focus, be examined at the centre of curvature, it gives there an momnt of longitudinal aberration $\frac{100}{100}$ of an inch, equal to twice the preceding. 'This latter, then, is the condition at the ecntre of curvature, to which such mirror must be bronght in order to converge parallel rays with exactness. In addition, strict watch must be kept upon the zones intermediate between the centre and edge, both by measurement with diaphragms of their aberration, and better yet, by observation of the regnlarity of the curve of that apparent solid, Fig. 16 , seen by the second test.

'This modification of the first test is literally a method of parabolizing by measure, and is capable of great precision when the eye learns to estinate where the exact focus of a zone is. 'The little irregularities found round the edges of the holes through the tin screen, Fig. 8, are in this respect of material assistance. 'They show, too, the increased optical or penetrating power that is gained hy increase of aperture. Minnte peculiarities, not visible under very high powers with a 10 inch diaphragm, become immediately perceptible even with less magnifying when the whole aperture is used, provided the mirror is spherical.

In the use of the second test precantions lave to be taken, as may be inferred from page 15, to set the opaque screen exactly in the proper position. The best method for ascertaining its location is, having received the image into the eye, placed purposely too near the mirror, to canse the screen to move across the cone of rays from the right towards the left side. A jet black shadow begins to advanee

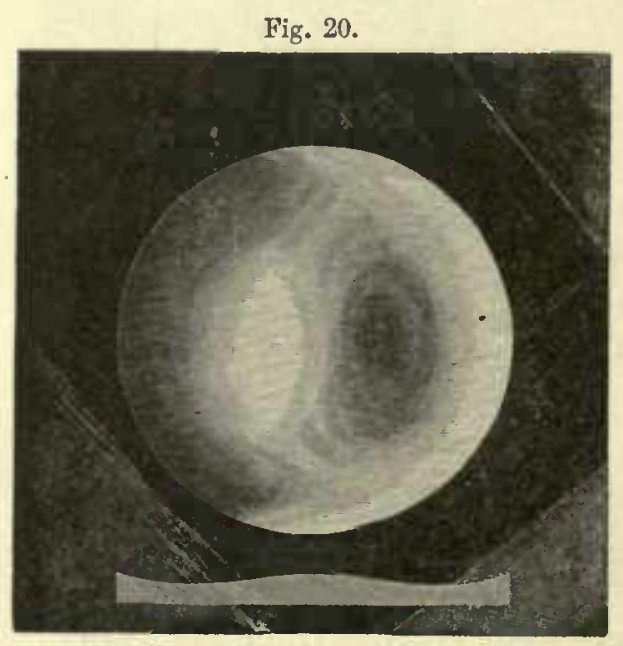

Adjusting the Opaque Screen. at the same time, and in the sane direction across the mirror. If the eye is then moved from the mirror sufficiently, this black sliadow can be made to originate by the same motion of the screen as before, from the left or opposite side of the mirror. Midway loetween these extremes there is a point where the advance is from neither side. This is the true position for the screen when it is resired to see the imperfections of the surface in highly exaggerated relief, as in Fig. 20, which represents the appearance of Fig. 12."

The interpretation of the lights and sluarlows upon the face of a mirror in this test is always easy, and the observer is not likely to mistake an elevation for a depression, if he bears in mind the fact that the surface under

I In order to examine Fig. 20, the book should be held with the left side of the page toward a window or lamp. The eye shonld also be at least two feet distant. The centre will then be seen to protrude, and the surface present the apparent section engraved below it. 
examination must always be regarded as illuminated by an oblique light coming from a somce on the side opposite to that from which the screen advances, coming for instance from the left hand side, in the above description.

In practice, the diaphragms commonly used for a $15 \frac{1}{2}$ inch mirror lave been as small as the light from the musilvered surface wonld allow. A six inch aperture at the centre, a ring an inch wide round the edge, and a two inch zone midway between the two.

\section{e. Machines.}

In the beginning of this section the difficulties into which I fell with Lord Rosse's machine were stated. 'These cansed it at the time to be abandoned. A machine based on the same idea as Mr. Lassell's beantiful apparatus was next constructed. It varied, however, in this, that the hypocycloidal curve was described partly by the rotation of the mirror, and partly by the motions of the polisher-the axes of the spindles canying the two being capalsle either of coincidence or lateral separation to a moderate extent. A great deal of time and labor was expended in grinding and polishing mumerous mirrors with it, but still the difficulty that had been so amnoying in the former machine persisted. Frequently, in fact generally, from six to eight zones of unequal focal length were visible, although on some occasions when the mirror was hyperbolic, the number was relneed to two. At first it was supposed that the fault lay with the polishing, the pitch accunnulating irregularly from being of improper softness, for it was found to be particularly prone to heap 11) at the centre. But after. I had introdnced a method of fine grinding with elntriated hone powder, which enablerl the glass to reflect light before the pitch polishing, it became evident that the zones were connected with the mode of motion of the mechanism. Many changes were made in the speed of its various elements, and a contrivance to control the irregular motion of the polisher introluced, but a really fine and miform parabolic surface was never obtained, the very best showing when finished zones of different focal lengtlis. Although it cannot be said that 1 have tried this machine thoroughly, for Mr. I a assell has produced specula of expruisite defining power with it, and must have avoided these imperfections to a great extent, yet the evident necessity of complicating the movement ${ }^{3}$ considerably, to avoid the polishing in rings, led me to adopt an entirely different. construction, which was nsed until quite recently. Although it has now been replaced by another machine, which is still better in principle, and gives fine results much more quickly, yet as it produced one parabolic surface that bore a power of more than 1000 , and as it serves to introduce the process of grinding, it is worthy of description. 'The action of machines for grinding and polishing has been thoronghly examined in my workshop, no less than seven different ones having been made at various times.

- Messrs. De La Rue and Nasinyth, who used one of Mr. Lassell's machines, as I have sinee learned, met with the same trouble, and were led to make two additions to the mechanism: 1 , to control the rotation of the polisher rigorously; and 2 , to give the whole speculnm a lateral motion, by which the intersecting points of the eurves deseribed by the polisher were regularly changed in distance from the centre of the mirror. Mr. Lassell had previously, however, introduced a contrivanee for this latter purpose himself. 
The machine, which is a simplification of Lord Rosse's, was intended to give spiral strokes. It differed from the original, however, in demanding a changeable stroke, and in the absence of the lateral motion. In another most essential feature it varied from both that and Mr. Lassell's, the mirror vas alucuys uppermost while polishing, and being uncomnterpoised escaped to as great an extent as possible from the effects of irregnlar pressure. 'To any one who has studied the deformations of a reflecting surface, and knows how troublesome it is to support a mirror properly, the advantage is apparent.

livg. 21.

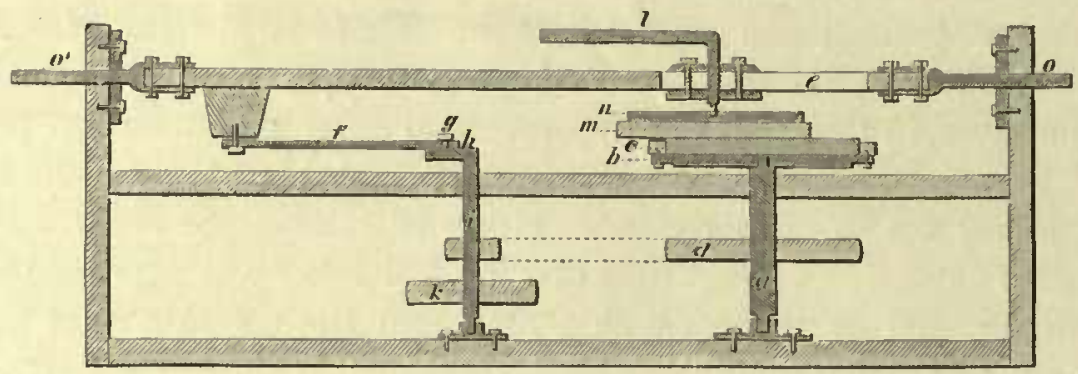

Polishing Machine.

The construction is as follows: A stout vertical shaft, ", lig. 21, carries at its top a circular table b, upon which the polisher a is screwed. Below a band-wheel d is fixed. Above the table, at a distance of four inches, a horizontal bar $e$ is arranged, so as to move back and forward in the direction of its length, and to earry with it by means of a screw $l$, the mirror $m$, and its iron back or cluck $n$. 'The bar is moved by a comecting rod $f$, attached to it at one end, and at the other to a pin $g$

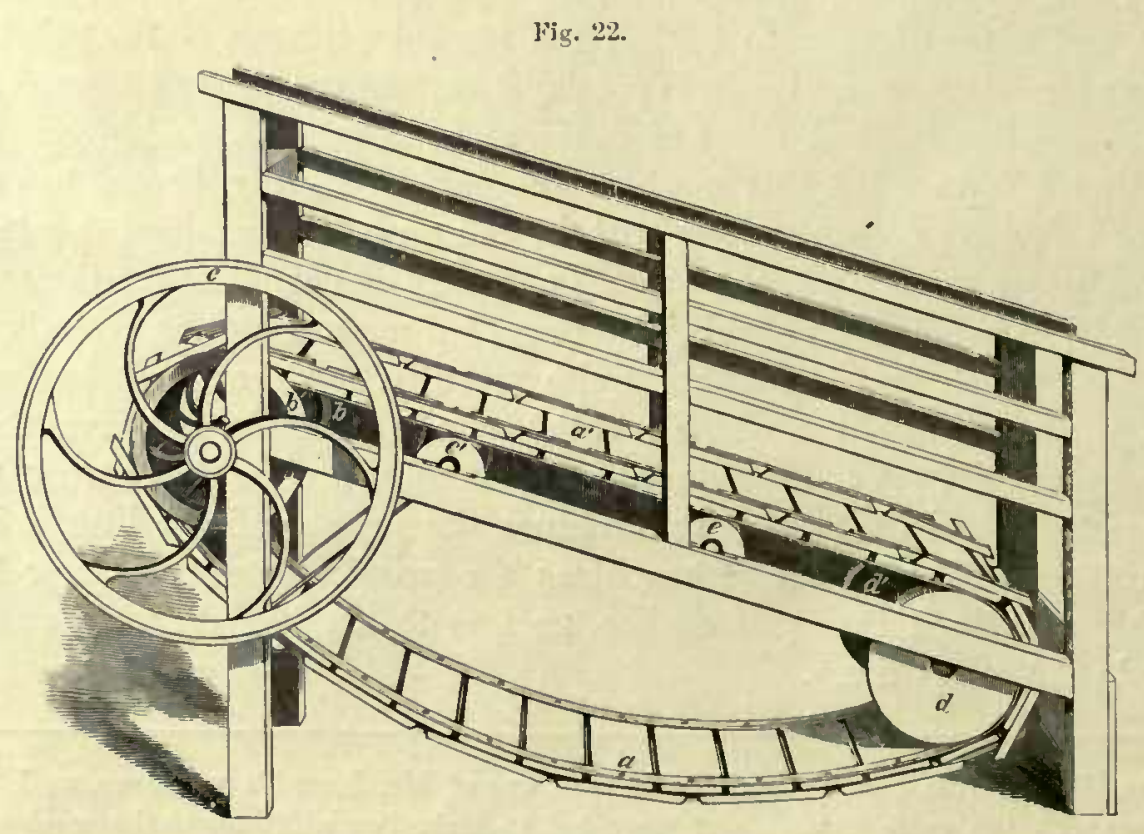

The liont Power.

moving a slot. 'This slot is in a crank $h$, carried by a vertical shaft $i$, near the former one $\ell$. 'The bund-wheel $l$ is connected with the foot power, Fig. 22. 'I'he 
machine, except those parts liable to wear by friction, is made of wood. The ends o o of the horizontal bar e, are defended by brass tubes working in mahogany, and have even now hit little shake, though many lundred thousands of reciprocations have been made.

'The foot power consists of an endless band with wooden treads "c', passing at one end of the apparatus over iron wheels $b, b$, which carry the band-wheel $c$ upon their axle. At the other end it goes over the rollers $d d$ '. 'Two pairs of intermediate wheels $e e^{\prime}$, serve to sustain the weight of the man or animal working in it. The treack are so arranged that they interlock, and form a platform, which will not yield downwards. Owing to its inclination when a weight is put on the platform $a^{\prime}$, it immediately moves from $l$ toward $l$ and the band-wheel turns. By a molerate exertion, equivalent to wilking up a slight incline at a slow rate, a power more than sufficient to polish a $15 \frac{1}{2}$ inch mirror is olstained. 'This machine, in which very little force is lost in overcoming friction, is frequently employed for dairy use, and is moved commonly in the State of New York by a sheep. I have generally myself walked in the one used by me, and have travelled some dings, during five homs, more than ten miles.

In order to give an idea of the method of using a grinding and polishing machine, the following extract from the workshop note-book is introduced:-

"A disk of plate glass $15 \frac{1}{2}$ inches in diancter, and $1 \frac{1}{1}$ inch thick was procurcd. It had been polished flat on both sides, so that its internal constitution might be seen. ${ }^{1}$ It was fastened upon the table $b$ of the machine, by four blocks of wood as at $c$, Fig. 21. Underneath the gliss were three thick folds of blanket, 15 inches in cliameter, to prevent scratching of the lower face, and avoid risk of fracture. A convex disk of lead weighing 40 pounds having been cast, was laid npon the npper surface of the grlass, and then the screw $l$ was depressed so as to catch in a perforated iron plate $n$, at the back of the lead $m$, and press downward strongly.

" Lmery as eoarse as the head of a pin having been introduced, through a hole in the lead, motion was commenced and continued for half an hour, an occasional supply of emery being given. 'The machine made 150 cight-inch cross strokes, and the mirror 50 revolntions per minnte. 'The grinder $m$ was occasionally restrained from turning by the hand. At the end of the time the detritus was washed away, and an examination with the gauge made. A spot 11 inches in cliameter, and $\frac{1}{6 v}$ of an inch deep, was found to have been ground out. 'The same process was contimed at intervals for ton homs, measurements with the gange being frequently made. 'The concave was then sufficiently deep. The leaden grinder' was kept of the right convexity by beating it on the baek when necessary. A finer variety of coarse emery, and after that flour emery were next put on, each for an hour. These left the surface moderately smooth, and nearly of the right focal length. 'The leaden grinder was then dismissed, and the iron one, Figr. 6, put in its stead. 'The

1 'The glass that I have user has generally been such as was intended for dearl-lights and sky. lights in ships. 
mirror was removed from its place, and ground upon a large picce of flat glass for ten minutes, to produce a circular outline to the concavity. It was cemented witl soft pitch to the concave iron disk, the counterpart of Fig. 6, and again recentred on the blanketed table $b$. Emeries of 3 and 20 seconds, and 1, 3, 10, 30, 60 minutes' elutriation were worked on it, an hour each. 'The rate of cross notion was rednced to 25 per minute to avoid heating, the mirror still revolving once for every three cross strokes. The screw pressure of $l$ was stopped. 'This produced a surfuce exquisitely fine, semi-transparent, and appearing as if covered with a thin film of dried milk. It conld reflect the light from oljects outside the window until an incidence of 45 degrees was reached, and at night was found to be bright enough for a preliminary examination at the centre of curvature.

"The polisher was constructed in the usual way (page 12), and being smeared with ronge was fastened to the table $b$, where the mirror had been. The latter warmed in water to $120^{\circ} \mathrm{F}$, was then put face downwards upon the former, and the screw $l$ so lowered as to cause no pressure. The machine was allowed to make 20 four-inch cross strokes per minute, and the polisher to revolve once for crery three strokes. The mirror being unconstrainedly supported on the polisher, was irregularly rotated by hand, or rather prevented from rotating with the polisher. The tendency of this method is to produce an almost spherical surfice. To chinge it to a paraboloid, it was only necessary when the glass was polished all over to increase the length of the stroke to 8 inches, and continue working fifteen minutes at a time, examining in the intervals by the tests at the centre of currature. The production of a polish all over oceupied about two hours, but the correction of figure took more time, on account of the frequent examinations, and the absolute necessity of allowing the mirror to come back to a state of equilibrium from which it had been disturbed when worked on the machine." I have seen a mirror which was parabolic when just off the machine, by cooling over night become spherical. And these heat changes are often succeded by other slower molecular movements, which continue to modify a surfice for many days after.

This correction, where time and not length of stroke is the governing agent, has once or twice been accomplished in fifteen minutes, but sonetimes lias cost sercral hours. If the figure should have become a hyperboloid of rerolution, that is, have its edge zones too long in compurison with the centre, it is only necessury to shorten the stroke to bring it back to the sphere, or even to overpass that and produce a surface in which at the centre of curvature the edge zones have too short a focal length (Fig. 12).

Very much less trouble from zones of unequal focal length was experienced after this machine and system of working were adopted. This was owing probably partly to the element of irregularity in the rotation of the mirror, anc partly to the fact that the surface is kept spherical until polished, and is then rapidly changed to the paraboloid. Where the adjustments of an apparatus are made so as to attempt to keep a surface parabolic for some hours, there is a strong tendeney for zones to appear, and of a width bearing a fixed relation to the stroke.

The method of producing reflecting surfaces next to be spoken of, is however that which has finally been adopted as the best of all, being cajable of forming 
mirrors which are as perfect as can be, and yet only requiring a short time. It is the correction of a surface by local retouches. In the account published by $\mathbf{M}$. Foncant, it appears that he is in France the inventor of this improvement.

'The mode of practising the retouches is as follows: Several disks of wood, as $a$, Fig. 23, varying from 8 inches to $\frac{1}{2}$ an inch in diameter, are to be provided, and covered with pitch or rosin of the usual hardness, in squares as at $e$, on one side. ${ }^{1}$ On the other a low cylindrical handle 4 ; is to be fixed. 'The mirror $a$, Fig. 24, laving been fined with the succession of emeries before described, is laid face upward on several folds of blanket, arranged upon a circular table, screwed to an isolated post in the centre of the apartment, which permits the operator to move completely round it. $\Lambda$ n ordinary barrel has generally supplied the place of the post, the head c, Fig. 24, serving for the circular table, and the rim ", preventing the mirror sliding off. 'The other end is fistened to the floor by four elects $d d$ '.

The large polisher is first moved over the surface in straight strokes upon every chord, and a moderate pressure is exerted. As soon as the mirror is at all brightened, perhaps in five minutes, the operation is to be suspended, and an examination at the centre of curvature made. By carefully turning round, the best diameter for support is to be found, and marked with a rat-tail file on the edge, and then the curve of the mirror ascertained. If it is nearly spherical, as will be the case if the grinding las been conducted with

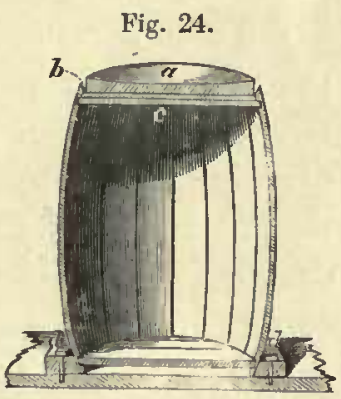

Section of Optician's Post. care and irregular heating avoided, it is to be replaced on the blanketed support, and the previous action kept up until a fine polisl, free from dots like stippling, is attained. This stage should occupy three or four hours. Another examination should reveal the same appearances as the precerling. It is next necessary to lengthen the radius of curvature of the edge zones, or what is much better shorten that of the centre, so as to convert the section eurve into a parabola. This is accomplished by straight strokes across every diameter of the face, at first with a 4 inch, then with a 6 inch, and finally with the 8 inch polisher. Examinations must, however, be made every five or ten minutes, to determine how much lateral departure from a direct diametrical stroke is necessary, to render the curve uniform out to the edge. Care must be taken always to warm the polisher, either in front of a fire or over a spirit lamp, before using it.

Perhaps the most striking feature in this operation is that the mirror presents continually a curve of revolution, and is not diversified with undulations like a ruffle: By walking steadily round the support, on the top of which the mirror is placed, there secms to be no tendency for such irregularities to arise.

If the correction for spherical abcriation should have proceeded too far, and the mirror become liyperbolic, the sphere can be recovered by working a succession

1 M. Foucault used plano-convex lenses of glass, of a radius of curvature sliglitly less than that of the mirlur, and covererl with paper on the convex face. 
of polishers of increasing size on the zone $a$, Fig. 16, intermediate between the centre and edge, cansing their centres to pass along every chord that can be described tangent to the zone.

A most perfect and rapid control can thus be exercised over a surface, and an uniform result very quickly attained. It becomes a pleasant and interesting occupation to produce a mirror. But two effects have presented themselves in this operation, which unfortunately bar the way to the very best results. In the first place the edge parts of such mirrors, for more than half an inch all aromed, hend backwards and become of too great focal length; and the rays from these parts cannot be united with the rest forming the image. In the second place, the smrface, when critically examined by the second test, is found to have a delicate wavy or fieecy appearance, not seen in machine polishing. ${ }^{1}$ Although the variations from the true curve implied by these latter greatly exaggerated imperfections are exceedingly small, and do not prevent a thermometer bulb in the sunshine appearing like a disk surromded by rings of interference, yet they must divert some mululitions from their proper direction, or else they would not be visible. All kinds of strokes have been tried, straight, sweeping circular, hypocycloidal, \&c. withont effecting their removal. M. Foncault, who used a paper polisher, also encountered them. Eventually they were imputed to the unequal pressure of the hand, and in consequence a machine to overcone the two above mentionerl faults of mammal correction was constructed.

The mirror $a$, is carried by an iron chuek or table $b$, covered with a triple

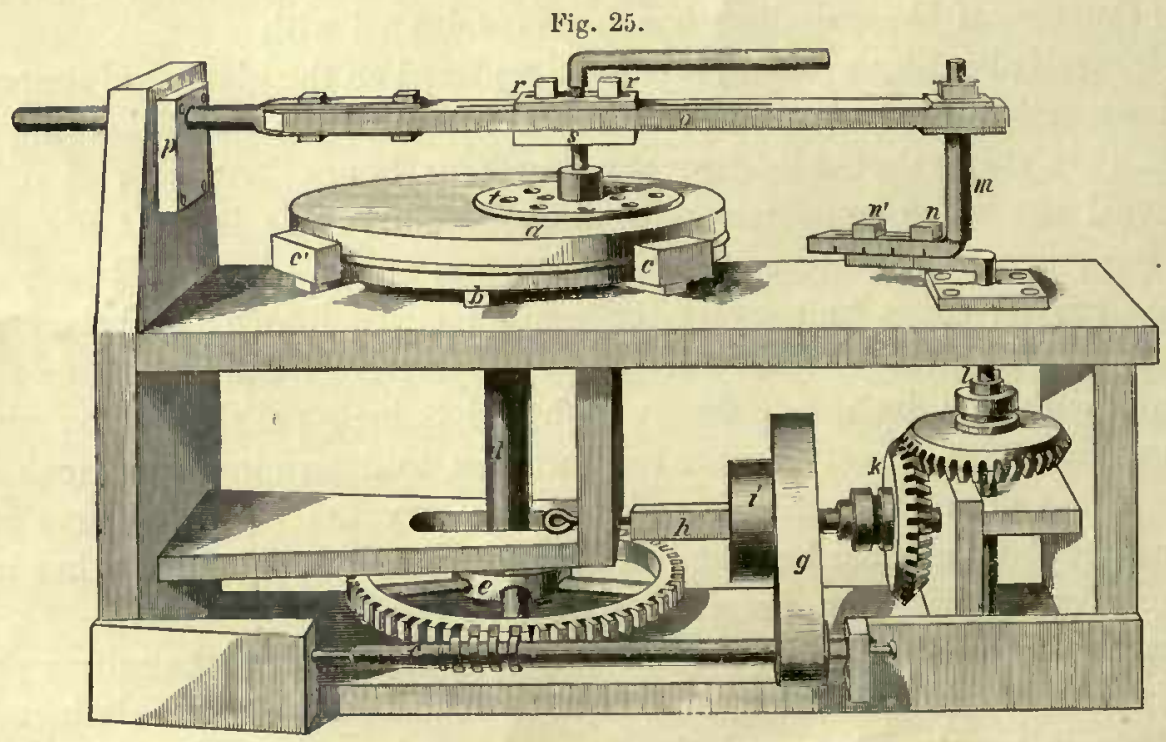

Machine for Local Corrections.

fold of blanket, and is prevented from slipping off by four elects $c c$ '. 'The vertical shaft $d$ passes through a worm-wheel $e$, the endless screw of which $f$, is driven by a band $g$, from the primary shaft $h$. At $i$ is the band-wheel for connection to

1 By this it is not meant that there is a rippled polish, like that produeed by buckskin. 
the foot-power. At one end of the primary shaft is firmly fixed the cogwheel $k$, which drives the crank-shaft $l$. Attached to the horizontal part of $l$, is the crankpin $m$. The two bolts $n n^{\prime}$ move in a slot, so that the crank-pin may be set at any distance from 0 to 2 inches, out of line with $l$. Above, the crank-pin carries one end of the bir $o$, the other end passing through an elliptical hole in the oak-block 1. Down the middle of the bar runs a long slot, throngh which the screw-pin $q$ passes, and which permits $q$ to be brought over any zone from the centre to the edge of the mirror $a$. It is retained by the bolts $r r^{\prime}$, which are tapped into $s$. 'The local polisher is seen at $t$. The curve which the centre of the local polisher describes upon the face of the mirror, varies with the adjustments. Fig. 26 is a reduction from one traced by the machine, the overlapping being seen on the left side. 'The nirror is not tightly confined by the eleets $c e^{\prime}$, for that would certainly injure the figure, but performs a slow motion of rotation, so that in no two successive strokes are the same parts of the edge pressed against them.

The local polishers are made of lead, alloyed with a small proportion of antimony, and are 8,6 , and 4 inches in cliameter, respectively. The largest and smallest are most used, the former on account of its size polishing most quickly, but the latter giving the truest surface. The rosin

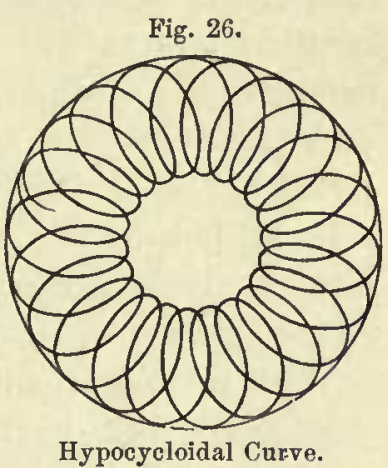
that covers them is just indentable by the thumb nail, and is arranged in a novel manner. The learlen basis, as seen at $t$, Fig. 25, is perforated in many places with holes, which permit evaporation, serve for the introduction of water where needed, and allow the rosin to sprearl freely. Grooves are marle from one aperture to another, and the rosin thus divided into irregular portions. 'The effects of the produetion of heat are in this way avoided.

The mirror may be ground and fined on this machine, in the same manner as on that described at page 21 , or it may be ground with a small tool 8 inches in diameter, as recently suggested by M. Foucanlt, the results in the latter case being just as gool a surface of revolution as in the former. It is best polished with the 8 inch, and a mulerate pressure may be given by the screw $q$, if the pitch is not too soft. This, however, tends to' leave an excavated place at the ecntre of the mirror, the size depending on the stroke of the crank $m$, which should be about 2 inches. The pin $q$ ought to be half way from the centre to the edge of the mirror, but must be oceasionally moved right or left an inch along the slot. When the surface is approaching a perfect polish, the warmed 4 inch polisher must be put in the place of the 8 ineh. The pin $q$ must be set exactly half-way between the centre and edge of the mirror, and the crank must have a stroke of two inches radins. The polisher then just goes up to the centre of the glass surface with one edge, and to the periphery with the other, while the onter excursion of the inner edge and inner excursion of the outer edge meet, and neutralize one another at a midway point. Wherever the edge of a polisher changes direction many times in sncession, on a surface, a zone is sure to form, unless avoided in this manner. All the foregoing description is for a $15 \frac{1}{2}$ inch mirror. 
By this system of local polishing the difficnlties of hent, distribution of polishing powders, irregular contact of the rosin, \&e. that render the attainment of a fine figure so uncertain usually, entirely disappear. A spherical surface is produced as above described, and afterwards by moving $q$ towarls the colge, and at the same time increasing the stroke, it is converted into a paraboloid. 'I'he fleecy appearance spoken of on a former pagre is not perceived, and the surface is good ahnost up to the extreme edge.

\section{(4.) Eyfr-Pifces, Plane Mirkors and 'Test Objects.}

The telescope is furnished with several eye-pieces of various construction, giving magnifying powers from 75 to 1200 , or if it were desired even higher. For the medium powers 300 and 600 Ramsden, or rather positive eye-pieces have been adopted. 'They differ, however, from the usual form in being achromatic, that is, each plano-convex is composed of a flint and crown, arranged according to formulas calculated by littrow. In this way a large flat field and absence of color are secured, and the fine images yielded by the mirror are not injured. For the higher powers, single achromatic lenses are used, and for the highest of all a Ross microscope.

With these means it has been found that the parabolic surfaces yielded by the processes before described, will define test objects excellently. Of close double stars they will separate such as $\gamma^{2}$ Andromeda, and show the colors of the components. In the ease of unequal stars which scem to be more severe tests, they can show the close companion of Sirins-discovered by Mr. Alvin Clark's magnificent refractor-the sixth component of $\theta^{1}$ Orionis, and a multitude of other difficult objects.

As an example of light collecting power, Debillisima between $\varepsilon$ and 5 Lyre is found to be quintuple, as first noticed by Mr. Lassell. In the $18 \frac{1}{2}$ inel specula of Herschel, it was only recorded as double, and, according to Admiral Smyth, I cord Rosse did not notice the fourth and fiftl components. Jupiter's moons show witl benutiful disks, and their difference in diameter is very marked. As for the body of that planet, it is literally covered with belts up to the poles. 'The bright and dark spots on Venus, and the farling illumination of her inner edge, and its irregularities are perceived even when the air is far from tranquil. Stars are often seen as disks, and withont any wings or tails, mless indeed the mirror shonld be wrongly placed, so that the best diameter for support is not in the perpendicular plane, passing through the axis of the tube.

It has been found that no advantage other than the decrease of atmospheric influence on the image, results from cutting down the aperture of these mirrors by diaphragms, while the disadvantage of reducing the separating power, is perecived at the same time. Faint objects can be better seen with the whole surface than with a reduced aperture, and this though apparently a property common to all reflectors and object glasses is not so in reality. A defective edge will often cause the whole field to be filled with a pale milky light, which will extinguish the fainter stars. Good definition is just as important for faint as for close objects.

The properties of these mirrors lave been best slown by the excellence of the 
photographs taken with them. Although these are not as sharp as the image seen in the telescope, yet it must not be supposed that an imperfect mirror will give just as good pictures. A photograph which is magnified to 3 feet, represents a power of 380 . As the original negative taken at the focus of the mirror is not quite $1 \frac{1}{2}$ inch in diameter when the moon is at its mean distance, it has to be enlarged about 25 times, and has therefore to be very sharp to bear it.

'The light collecting power of an minsilvered mirror is quite surprising. Witl a $15 \frac{1}{2}$ inch, the companion of a Lyre can be perceived, though it is only of the eleventh magnitude. The moon and other bright objects are seen with a purity highly pleasing to the eye, some parts being even more visible than after silvering.

In order to finish this description, one part more of the optical apparatus requires to be noticed-the plane mirrors. In the Newtonian reflector the image is rejected out at the side of the tube by a flat surface placed at $45^{\circ}$ with the optical axis of the linge concave. ' If this secondary mirror is either convex or concave, it modifies the image injuriously, causing a star to look like a cross, and this though the curvature be so slight as hardly to be perceptible by ordinary means. For a long time I used a piece $3 \times 5$ inches, which was cut from the centre of a large looking-glass accidentally broken, but eventually found that by grinding three pieces of 6 inches in diameter against one another, and polishing them on very hard piteh, a nearer approach to a true plane could be made. They were tested by being put in the telescope, and observing whether the focus was lengthened or shortened, and also by trial on a star. When sufficiently good to bear these tests, a piece of the right size was cut out with a cliamond, from the central parts.

\section{§ 2. TIE TELESCOPF MOUNTING.}

The telescope is mounted as an altitude and azimuth instrument, but in a manner that causes it to differ from the usual instrument of that kind. The essential feature is, that the eye-piece or place of the sensitive plate is stationary at all altitudes, the observer always looking straight forward, and never having to stoop or assume inconvenient and constrained positions.

'The stationary eye-piece mounting was first used by Miss Caroline Hersehel, who had a 27 inch Newtonian arranged on that plan. Fig. 27. (Smytlı's Celestial Cycle.)

Subsequently it was applied to a large telescope by $\mathrm{Mr}$. Nasmyth, the eminent engineer, but no details of his construction have reached me. IIe used it for making drawings of the moon, which are said to be excellently executed.

When it becanie necessary to determine how my telescope should be mounted, I was strongly urged to make it

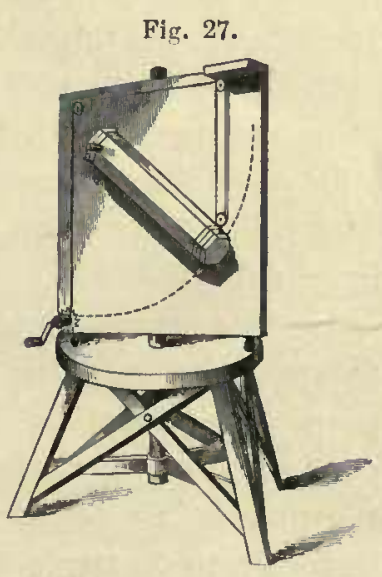

Miss Herschel's Telescope.

1 A right-angled prism cannot be used with advantage to replace the plane silvered mirrors, because it transmits less light than they reflect, is nore liable to injure the image, and the glass is apt to be more or less colored. Its great size and cost, one three inches square on two faces being required for my purposes, has also to be considered. 
an equatorial. But after reflecting on the fact that it was intended for photography; and that absolute freedom from tremor was essential, a condition not attained in the equatorial when driven by a elock, and in addition that in the case of the moon rotation upon a polar axis does not suffice to connteract the motion in declination, I was led to adopt the other form.

A great many modifications of the original idea have been made. For instance, instead of counterpoising the end of the tube containing the mirror by extending the tube to a distance beyond the altitude or horizontal axis, I introduced a system of counterpoise levers which allows the telescope to work in a space little more than its own focal length across. 'This construction permits both ends of the tube to be supported, the lower one on a wire rope, and gires the greatest freedom from tremor, the pairts coming quickly to rest after a movement. In the use of the telescope for. photography, as we shall sce, the system of bringing the mass of the instrument to complete rest before exposing the sensitive plate, and only driving that plate itself by a clock, is always adopted.

The obvious disadvantage connected with the alt-izimuth mounting-the difficulty of finding some objects-has not been a source of embarrasment. In fact the instability of the optical axis in reflecting instruments, if the mirror is unconstrainedly supported, as it should be, renders them unsuitable for determinations of position. A little patience will enable an obsarver to find all necessary tests, or curious objects.

'The mounting is divided into: a. 'The Tube; and b. The supporting frame.

\section{a. The Tube.}

The telescope tube is a sixteen sided prism of walnut wood, 18 inches in diameter, and 12 feet long. 'The staves are $\frac{3}{8}$ of an inch thick, and are hoojed together with four bands of brass, capable of being tightened by screws. Inside the tube are placed two rings of iron, half an inch thick, reducing the internal diameter to about 16 inches. At opposite sides of the upper end of the tube are screwed the perforated trunions $a$, Fig. 28 (of which only one is shown), upon which it swings. Surrounding the other end is a wire rope $b b^{\prime} b^{\prime \prime}$, the ends of which go over the pulleys $c$ ( $c^{\prime}$ not shown) on friction rollers, and terminate in disks of lead $d d^{\prime}$. These comnterpoises are fastened on the ends of levers $e e^{\prime}$, which turn below on a fixed axle $f$.

$\mathrm{By}$ this arrangement as the tube assumes a horizontal position and becomes, so to speak, heavier, the comterpoises do the same, while when the tube becomes perpendicular, and most of its weight falls upon the trumnions, the comterpoises are carried mostly by their axle. A continual condition of equilibrium is thus reached, the tube being easily raised or depressed to any altitude desired. It is necessary, however, to constrain the wire rope $b b^{\prime} b^{\prime \prime}$, to move in the are of the circle described by the end of the tube and ends of the levers and hence the twelve rollers or gride pulleys $g g^{\prime} g^{\prime \prime}$. Over some of the same pulleys a thin wire rope $h_{\ell} h^{\prime}$ rums, but while its ends are fastened to the lower part of the tulse at 7 , the central parts go twice around a roller connected with the winch $i$, near the cye-piece, thus cuabling the observer to move the telescope in altitude, without taking the eye from the eyc-piece. 
The iron wire rope required to be carefully made, so as to avoid rigidity. It contains $2 \frac{1}{3}$ miles of wire, $\frac{1}{10} \overline{0}$ of an inch in diameter, and has 300 strands. Each single wire will support 7 pounds It is, however, more flexible than a hempen rope of the same size, owing to its loose twisting.

At the lower end of the tube, at the distance of a foot, and crossing it at right angles, held by three bars of iron $i i^{\prime} i^{\prime \prime}$, Fig. 29, is a circular table of oak $e$, which

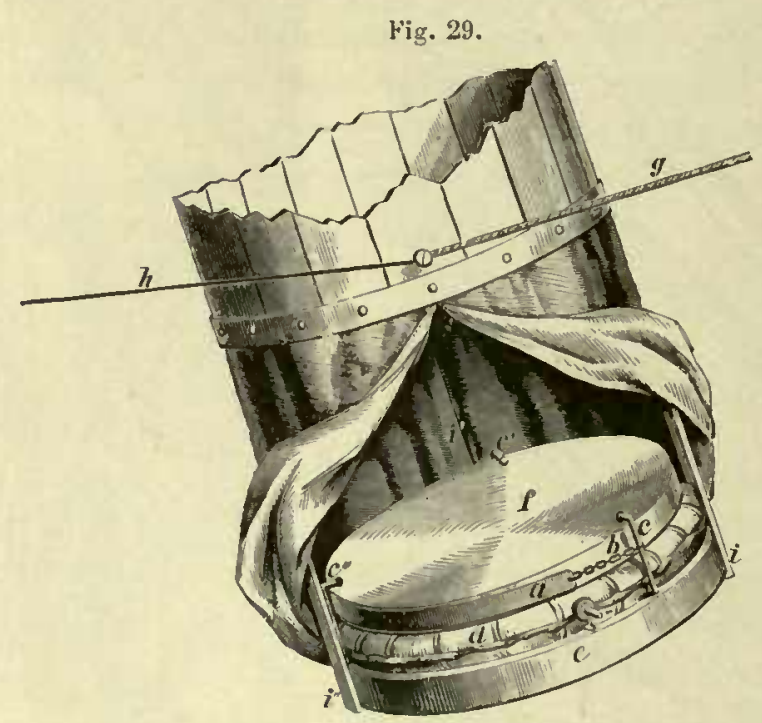

The Mirror Support.

carries an India-rubber air sac $d$, and upon this the mirror $f$ is placed. The edge support of the mirror is furnished by a semicircular band of tin-plate $a$, lined inside with cotton, and fistened at the ends by links of chain $l$, ( $l$ ' not seen) to two serews $c c^{\prime} ; g$ and $h$ are the wire ropes, markerl $b$ and $h$ in Fig. 28.

Instead of the blanket support which Herschel found so advantageous, M. Foulcault has suggested this use of an air sac. In his instrument there is a tube going up to the observer, by which he may adjust its degree of inflation. It requires that there should be three bearings $e e^{\prime} e^{\prime \prime}$, in front of the mirror, against which it may press when the sac behind is inflated, otherwise the optical axis is altogether too instable, and objects cannot be found. The arrangement certainly gives beantiful definition, bringing stars to a disk when the glass just floats, without touching its front bearings. The first sac that I made was composed of two eircular sheets of India-rubber eloth, joined around the edges. But this could not be used while photographing, because the image was kept in a state of continuous oscillation if there was a breeze, and even under more favorable circumstances took a long time to come to rest. It was not advisable to blow the mirror hard up against its threc front bearings, in order to avoid the instability, for then every point in of an object became triple. 'To the eye the oscillations were not offensive, because the swaying image was sharp.

Subsequently, however, an air chair cushion was procured, and as the surface was flat instead of convex the difficulty became so much less, that the blanket support was definitely abandoned. It is necessury that the mirror should have free play in 
the direction of the length of the tube when this kind of support is used, and that is the reason why the tin edge hoop must terminate in links of chain.

'The interval, eight or ten inches, which separates the face of the mirror from the tube, is occupied by a curtain of black velvet, confined below by a drawing cord and tacked above to the tube. 'Ihis permits access to the mirror to put a glass cover on it, and when shut down stops the current of air rushing up. When the instrument is not being used this curtain is left open, because the mirror and tube are in that case kept more uniform in temperature with the surrounding air.

In spite of such contrivances there is still sometimes a strong residual current in the tube. I have tried to overcome it by covering the mouth of the tube with a sheet of flat glass, but have been obliged to abandon that because the images were injured. At one time, too, when it was supposed that the curront was partly from the observer's body, heated streams of air going out around the tube, the aperture in the dome was closed by a conical bag of muslin, which fitted the mouth of the telescope tightly. The only advantages resulting were mere bodily comfort and a capability of perceiving fainter objects than before, because the sky-light was shut off.

\section{b. The Supporting Frame.}

The frame which carries the preceding parts is of wood, and rests on a vertical axis $a$, Fig. 30, turning below in a gun-metal cup $b$, supported by a marble block

Fig. 30.

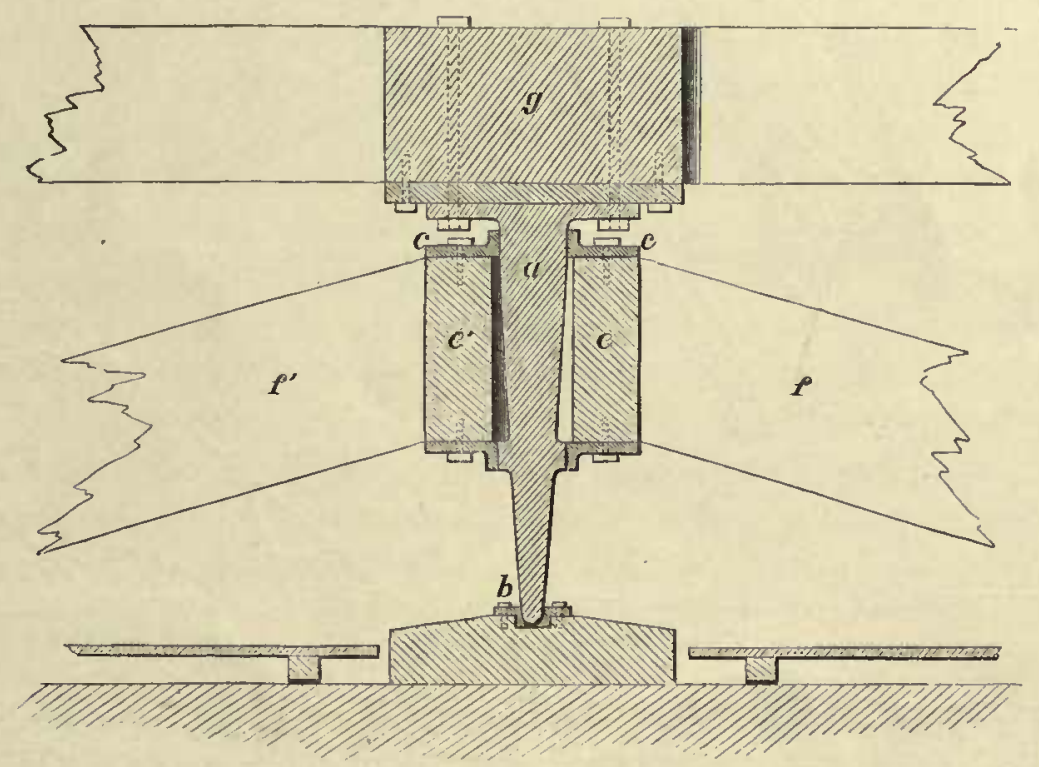

Section of Azinuth Axis.

resting on the solid rock. The upper end of the axis is sustained by two collars, one $c c^{\prime}$ above, and the other below an intermediate triangular box $e e^{\prime}$ from the sides of which three long beams $f$ f $f 12 \times 3$ inches diverge, gradually declining till they meet the solid rock at the limits of the excavation in which the observatory 
is placed. 'These beams are fastened together by eross-picees // //, Fig. 31, and go through the floor in spaces $h \hbar \hbar$, so contrived that the floor does not touch them. At the ends they are cased with a thick leaden sheathing, to deaden vibration and prevent the access of moisture.

Fig. 31 .

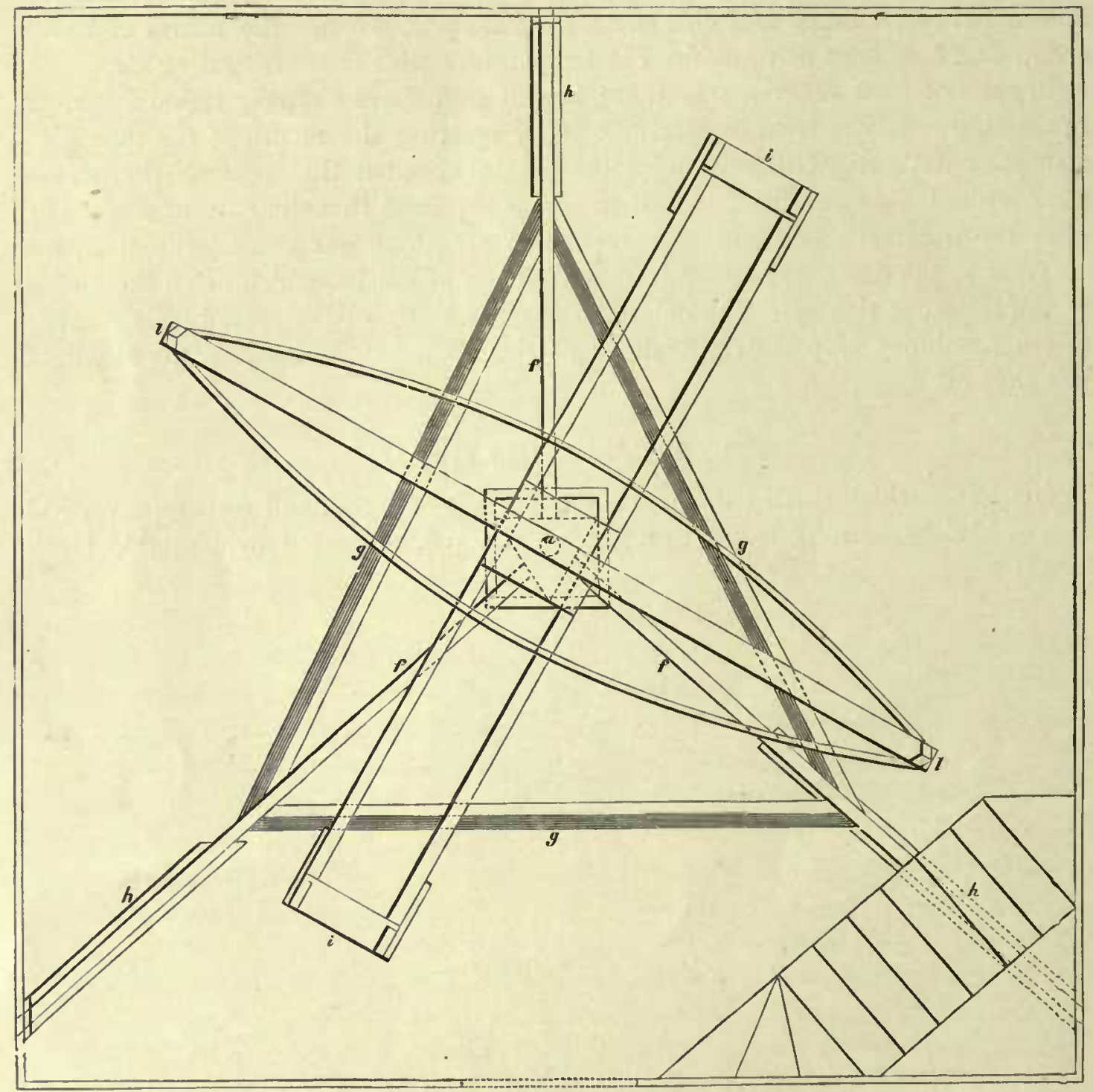

Plan of Observatory (lower floor).

'This tripod support in connection with the sustaining of the telescope by the wire rope, gives that steadiness which is so essential in photography. Only a slight amount of force, about two pounds, is required to move the instrument in azimuth, though it weighs almost a thousand pounds.

The plan of the frame centrally carried by the axis $a$ is as follows: From the corners of a parallelogram $i$ i $(2 \times 13$ feet $)$ of wooden beams, cight inches thick and three inches broar, perpendiculars $n n^{\prime}$, Fig. 28 , rise. At the top they are connected by lighter pieces to form a parallelogram, similar to that below, and just 
large enongh to contain the tube of the telescope. At right angles to the parallelogram below, and close npon it, a braced bar $o o^{\prime}$, Fig. 28, crosses. From its extremities four slanting braces as at $p p^{\prime}$, Fig. "28, go to the colners of the upper parallelogram, and combine to give it lateral support. At the top of one close pair of the perpendiculars $u^{\prime}$, Fig. 28, are bronze frames carrying friction rollers upon which the trumnions move, while similarly upon the other pair $n$ are two pulleys, also on friction rollers, for the wire rope coming from the counterpoises.

Movement in altitude is very easily accomplished, and with the loft hand upon the winch $i$, under high powers, both altitude and azimuth motions are controlled, and the right hand left free. The whole apparatus works so well, that in ordinary observation the want of a clock movement lias not been felt. Of course for photograpliy that is essential.

\section{§3. 'TIIE CLOCK MOVEMENT.}

The apparatus for following celestial bodies is divided into two parts; a. The Sliding Plate-holder; and b. 'Tlıe Clepsydra. In addition a short description of the Sun-Camera, c, is necessary.

\section{a. The Sliding Plute-leolder.}

Mr. De La Rue, who has done so much for celestial photograpliy, was the first to suggest photographing the moon on a sensitive plate, cumied by a frame moving in the apparent direction of her path. He never, however, applied an automatic driving mechanism, but was eventually led to use a clock which eaused the whole telescope to revolve npon a polar axis, and thus compensate for the rotation of the earth, and on certain occasions for the motion of the moon herself. In this way he lias prodnced the best results that have been obtained in Europe. Lord Rosse, too, employed a similar sliding plate-lıolder, but provided with clock-work to move it at an appropriate rate. 1 lave not been able as yet to procure any precise account of either of these instruments.

'The first photographic representations of the moon ever made, were taken by my father, Professor John W. Draper, and a notice of them published in his quarto work "On the Forees that Organize Plants," and also in the September number, 1840, of the London, Edinburgh, and Dublin Philosophical Magazine. He presented the specimens to the New York Lyceun of Natural History. 'The Secretary of that Association lias sent me the following extract from their minutes:-

"March 23d, 1840. Dr. Draper announced that he had succeeded in getting a representation of the moon's surface by the Daguerreotype ..... 'The time occupied was 20 minutes, and the size of the figure about 1 inch in diameter. Daguerre had attempted the same thing, but did not succeed. This is the first time that anything like a distinet representation of the moon's surface has been obtained.

"Roit. H. Brownne, Secretary."

As my father was at that time however nuch oceupied with experiments on the Chemical Action of Light, the Influence of Light on the Decomposition of Car-

5 June, 1864. 
bonic Acid by Plants, the Fixed lines of the Spectrum, Spectrmm Analysis, \&c., the results of which are to be found scattered through the l'hilosophical Magnzine, Silliman's Journal, and the Journal of the Franklin Institute, lie never pursued this very promising subject. Some of the pictures were taken with a three inch, and some with a five inch lens, driven by a heliostat.

In $1850, \mathrm{Mr}$. Bond, taking advantage of the refractor of 15 inches aperture at Cambridge, obtained some fine pictures of the moon, and subsequently of double stars, more particularly Mizar in Ursa Major. 'The driving power, in this instance, was also applied to move the telescope upon a polar axis.

Besides these, several English and contimental observers, Messrs. Jartuup, Phillips, Crookes, Father Secchi, and others, have worked at this branch of astronomy, and, sinec 1857, Mr. Lewis M. Rutherfurd, of New York, has taken many exquisite lunar photographs, which compare fitvorably with foreign ones.

But in none of these instances laas the use of the sliding plate-holder been persisted in, and its advantages brought into view. In the first place it gets rid completely of the difficulties arising from the moon's motion in declination, and in the second, instead of injuring the photograph by the tremors producerl in moving the whole heavy mass of a telescope weighing a ton or more, it only necessitates the driving of an arrangement weighing scarcely an ounce.

My first trials were with a frame to contain the sensitive plate, held only at three points. 'Two of these were at the ends of screws to be tumerl by the hands, and the third was on a spring so as to maintain firm contact. This apparatus worked well in many respects, but it was found that however much care miglit be taken, the hands always cansed some tremor in the instrument. It was evident then that the difficulty from friction which besets the movements of all such delicate machinery, and causes jerking and starts, would have to be avoirled in some other way.

I next constructed a metal slide to rum between two parallel strips, and ground it into position with the greatest care. 'This, when set in the direction of the moon's apparent path, and moved by one screw, worked better than the preceding. But it was soon perceived that although the strips.fitted the frame as tightly as practicable, an arlhesion of the slide took place first to one strip and then to the other, and a sort of unclulatory or rermicular progression resulted. The amount of deviation from a rectilinear motion, though small, was enough to injure the photographs. At this stage of the investigation the regiment of rolunters to which 1 belonged was called into active service, and I spent several months in Virginia.

My brother, Mr. Daniel Draper, to whose mechanical ingenuity I have on several occasions been indebted for assistance in the manifold difficulties that have arisen while constructing this telescope, continued these experiments at intervals. Ile presented me on my return with a slide and sand-clock, with which some excellent photographs have been taken. He harl found that unless the slide above mentioned was made ungovernably long, the same tronble contimuer. He then ceased catching the sliding frame $h$, Fig. 32, by two opposite sides, and marle it rim along a single steel rod $a$, being attached by ineans of two perforated plates of brass $b, b$. The cord $i$ going to the sand-clock, was applied so as to pull as nearly as possible in the direction of the rorl. A piece of cork $c$, gave the whole steadiness, and yet 
softness of motion. 'The lower end of the frame was prevented from swinging back ind forward by a steel pin $d$, which played along the glass rod $e$. All these parts were attached to a frame $h$, fitting on the eyepiece loolder, and permitting the rod e to change from the horizontal position in which it is liere drawn, to any angular one desired. 'The thumb-screw $f$ retained it in place; $g$ and $g$ are pulleys which permit the cord to change direction.

Subsequently, a better method of examining the uniformity of the rate, than by noticing the sharpness of the photograph produced, was invented. It consists in arranging a fixed microscope, magnifying about 40 times, at the back of the ground glass plate, which fits in the same slide as the sensitive plate. By watching the granulated appearance pass before the eye, as the slide is moved by the

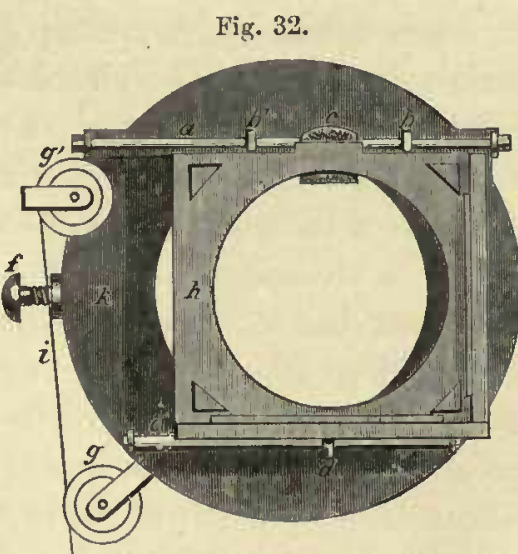

Sliding Plate-holder. clock, the slightest variation from uniformity, any pulsatile or jerking movement is rendered visible. By the aid of this microscopic exaggeration, it was seen that occasionally, when there had been considerable changes in temperature, the steadiness of the motion varied. 'This was traced to the irregular slipping of $b, b^{\prime}$.

A different arrangenent was then adopted, by which a lunar crater can be kept bisected as long as is necessary, and which gives origin to no irregularities, but pursues a steady course. 'The principle is, not to allow a slipping friction anywhere, but to substitute rolling friction, upon wheels turning on points at the ends of their axles. The following wood-cut is half the real size of this arrangement.

Fig. 33.

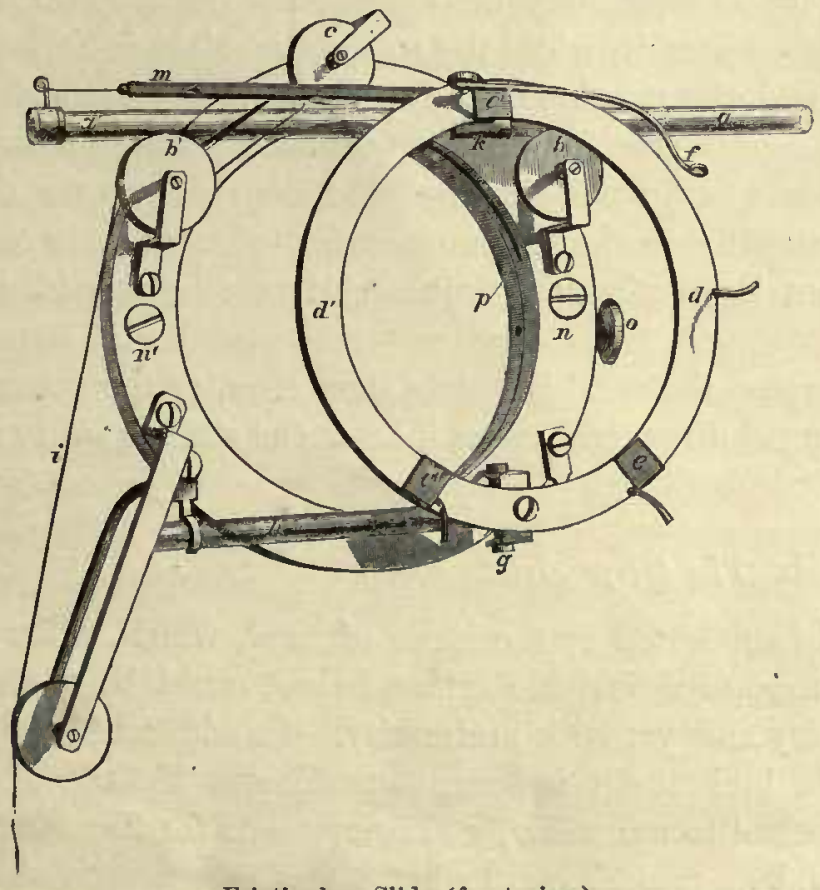

Frictionless Slide (front view).

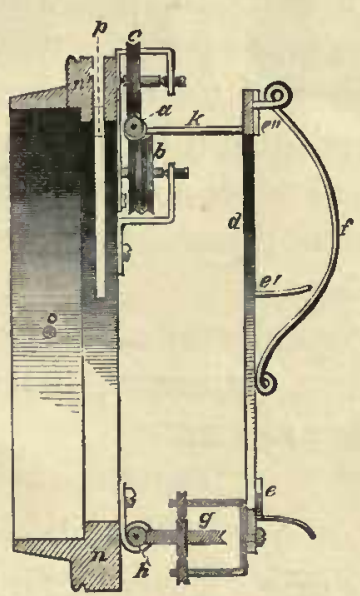

Sectional view. 
A glass rod $a, a^{\prime}$, Fig. 33, is sustained by two wheels $b, b^{\prime}$, ancl kept in contaet with them by a third friction roller $c$, pressed downward by a spring. 'This rorl earries a circular frume $d, d^{\prime}$, upon which at $e, e^{\prime}, e^{\prime \prime}$, are three gliss holders and platinum catches. A spring $f$ holds the sensitive plate in position, by pressing against its back. 'The circular frame $d$ is kept in one plane by a fourth friction roller $g$, which runs on a glass rod $h$, and is kept against it by the inward pressure of the overhanging frame $d$. The cord $i$ is attached to the arm $l ;$, and pulls in the direction of the glass rod $\alpha$. From $m$ to a fixed point near $b$, a strip of elastic Indiarubber is stretched, to keep the cord tight. 'The ring of brass $n$, $u^{\prime}$ carries the whole, serving as a basis for the stationary parts, and in its tmm being fastened to the eyepiece holder, so as to allow the glass rod a to change direction, and be brought into coincidence with the apparent path of the moon. At $o$ is a thumbscrew or clamp 'Through the ring $n, n^{\prime}$, a groove $p$ is cut, into which a pieec of yellow glass may be placed, when the actinic rays are to be shut off from the plate.

Since this contrivance has been completed, all the previous difficulties have vanished. The moving of a plate can be accomplished with such precision, that when the atmosphere was steady, negatives were taken which have been enlarged to three feet in diameter.

The length of time that such a slide can be made to run is indefinite, depending in my case on the size of the diagonal flat mirror, and aperture of the eyepiece holder. I can follow the moon for nearly four minutes, but have never required to do so for more than fifty scconds. At the mouth of the instrument, where no secondary mirror is necessary, the time of rumning could be increased.

The setting of the frictionless slide in angular position is accomplished as follows: A ground glass plate is put into it, with the ground face toward the mirror. Upon this face a blaek line must have been traced, precisely parallel to the rorl ". 'This may be accomplished by firmly fixing a pencil point against the ground side, and then drawing the frame $d$ and glass past it, while the rest of the slide is licld fast. As the moon passes across the field, the position of the apparatus must be changer, until one of the craters runs along the line from end to end. A cross line drawn perpendicular to the other, serves to adjust the rate of the clepsydra as we shall see, and when a crater is kept steadily on the intersection for twice or three times the time demanded to secure an impression, the adjustment may be regarded as complete.

It is necessary of course to expose the sensitive plate soon after, or the apparent path of the moon will have changed direction, mless incleed the slide is set to suit a future moment.

\section{b. The Clepsyglre.}

My prime mover was a weight supported by a column of sand, whicl, when the sand was allowed to rmn out through a variable orifice below, conld be made to descend with any desired velocity and yet with uniformity. In addition, by these means an unlimited power could be brought to bear, depending on the size of the weight. Previously it was proposed to use water, and compensate for the decrease in flow, as the colmmm shortened, by a conical vessel; but it was soon pereeived that 
as each drop of water escaped from the funnel-shaped vessel, only a corresponding weight would be bronght into play. 'This is not the case with sand, for in this instance every grain that passes out canses the whole weight that is supported by the column to come into action. In the former instance a movement consisting of a scries of periods of rest and periods of motion occurs, because power has to aceumulate by floating weight lagging behind the descending water, and then suddenly overtaking it. In the latter case, on the contrary, there is a regular descent, all minor resistances in the slide being overcome by the steady application of the whole mass of the weight.

When these advantages in the flow of sand were ascertained, all the other prime movers were abandoned. Mercury-clocks, on the principle of the hydrostatic paradox, air-clocks, \&c., in great variety, had been constructed.

The sand-clock consisted of a tube $*$ (Fig. 34), eighteen inches long and one and a half in cliameter, nearly filled with sand that had been raised to a bright red heat and sifted. Upon the top of the sand a leaden weight $b$ was placed. At the botton of the tule a peculiar stopcock, scen at (2) enlarged, regulated the flow, the amount passing depending on the size of the aperture $d$. This stopcock consisted of two thin plates, fixed at one end and free at the other. 'The one marked $e$ is the adjusting lever, and its aperture moves past that in the plate $g$. The lever $f$ serves to turn the sand oft altogether, without disturbing the size of the other aperture, which, once set to the moon's rate, varies but slightly in short times. A movable cover 7 , perforated to allow the cord $i$ to pass throngh, closed the top, while the ressel 7 : retained the escaped sand, which at suitable times was returned into the tube $a$, the weight $b$ being temporarily lifted out. From the clock the cord $i$ communicated motion to

lig. 34 .

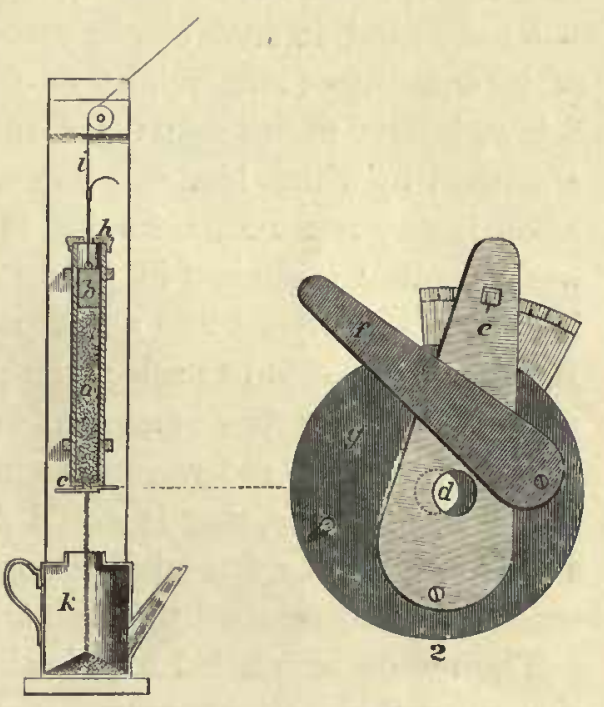

The Sand-Clock. the frictionless slide, as shown in Fig. 33. This cord should be as inelastic as possible, consistent with pliability, and well waxed.

One who has not investigated the matter would naturally suppose that the flow of sand in such a long tube would be much quicker when the tube was full than when nearly empty, and that certainly that result would oceur when a heavy weight was put on the shifting mass. But in neither case have I been able to detect the slightest variation, for, although by shaking the tube a diminution of the space oceupied by the sand may be caused, yet no increase of weight tried could accomplish the same reduction. These peculiarities seem to result from the sand arehing as it were across the vessel, like shot in a narrow tube, and only yielding when the under supports are removed. In blasting, a heavy charge of gunpowder can be retained at the bottom of a hole, and made to split large masses of rock, by filling the rest of the hole with dry sand. 
I believe that no prime mover is more suitable than a sand-clock for purposes where steady motion and a large amount of power are demanded. 'The simplicity, for instance, of a heliostat on this plan, the large size it might assume, and its small cost, would be great recommendations. In these respects its advantages over wheelwork are very apparent. The precision with which such a sand-clock goes may be appreciated when it is stated, that under a power of 300 a lmmer crater can be kept bisected for many times the period required to photograph it. 'To secure the greatest accuracy in the rate of a sand-clock, some precantions must be taken. 'I'he tube shonld be free from dents, of uniform diameter, and very smooth or polished inside. Water must not be permitted to find access to the sand, and hygrometric varieties of that substance shonld be avoided, or their salts washed ont. The sand shonld be burned to destroy organic matter, and so sifted as to retain grains nearly equal in size. 'The weiglit, which may be of lead, must be tumed so as to go easily down the tube, and must be eovered with writing paper or some other hard and smooth material, to aroid the proneness to adhesion of sand. A long bottle filled with mercury answers well as a substitute.

I have used in such clocks certain metallic preparations: Fine shot, on account of its equality of size, might do for a very large clock with a considerable opening below, but is unsuitable for a tube of the size stated above. 'There is, however, a method by which lead can be reduced to a divided condition, like fine gunpowder, when it may replace the sand. If that metal is melted with a little antimony, and while cooling is shaken in a box containing some plumbago, it breaks up at the instant of solidifying into a fine powder, which is about fire times as heary as sand. If after being sifted to scleet the grains of proper size, it is allowed to run throngh a small hole, the flow is seen to be entirely different from that of sand, looking as if a wire or solid rod were descending, and not an aggregation of particles. It is probable, therefore, that it wonld do better than sand for this purpose. I have not, however, given it a fair trial, because just at the time when the experiments with the sand-clock had reached this point, I determined to try a elepsydra as a prime mover.

The reason which led to this change was that it was observed on a certain occasion when the atmosphere was steady, that the photograplis did not correspond in sharpness, being in fact no better than on other nights when there was a considerable flickering motion in the air. A further investigation showed that in these columns of sand there is apt to be a minute vibrating novement. At the plateholder above this is converted into a series of arrests and advances. On some occasions, however, these slight deviations from continuous motion are cntirely absent, and grenerally, indeed, they cammot be seen, if the parts of the image secm to vibrate on account of eurrents in the air. By the aid of the microscopic exaggeration described on a former page-which was subsequently put in practicethey may be observed easily, if present.

When the negative produced at the focus of the great mirror is intended to be enlarged to two feet or more in size, these movements injure it sensibly. A rariety of expedients was resorted to in order to avoid them, but none proved on all occasions successful.

It is obvious that in a water-clock, where the mobility of the fluid is so much 
greater than that of solid grains, this difficulty would not arise. The following contrivance in which the fault of the ordinary clepsyclia, in varying rate of flow as the column shortens, is avoided, was next made. With it the best results are attainable, and it seems to be practically perfect.

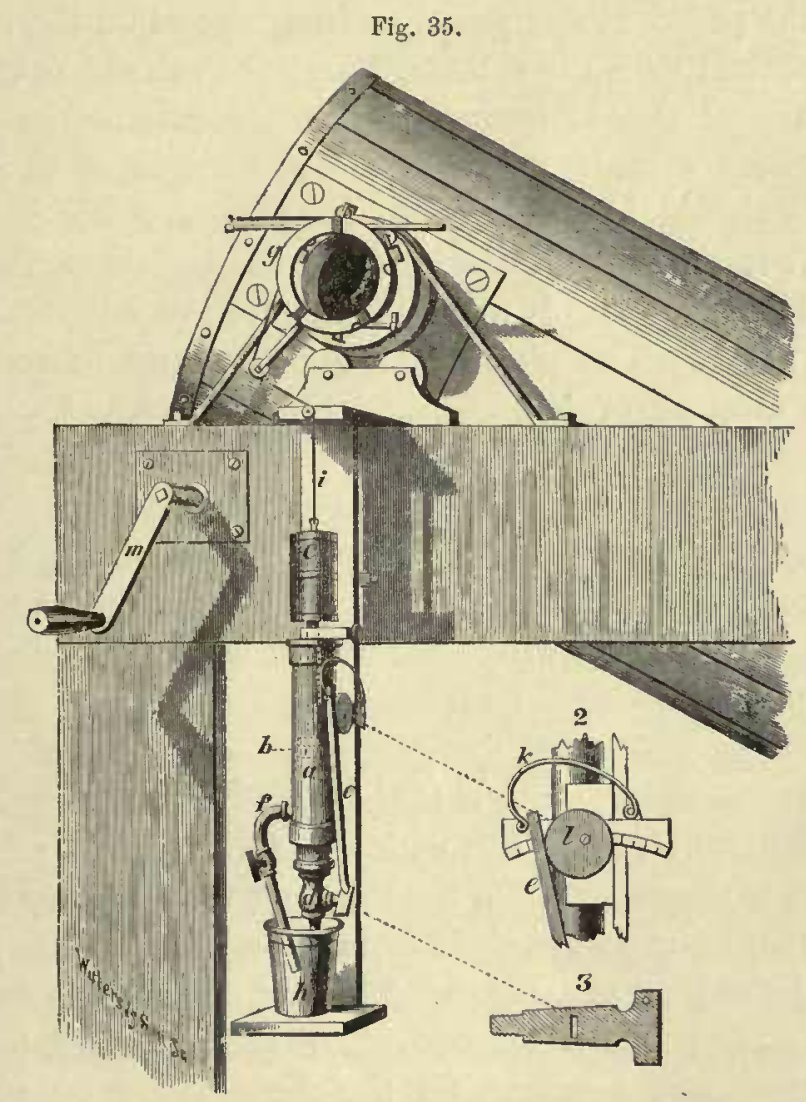

The Clepsydra.

It consists of a cylinder $a$, in which a piston $b$ moves watertight. At the top of the piston rod is a leaden five-pound weight $e$, from which the cord $i$ goes to the sliding plateholder $g$. The lower end of the cylinder terminates in a stopeock $d$, the handle of which carries a strong index rod $e$, moving on a divided arc. At $f$ a tube with a stopeock is attached. Below, a vessel $h$ receives the waste fluid.

In using the clepsydra the stopcock of $f$ is opened, and the piston being pulled upwards, the eylinder fills with water from $h$. The stopcock is then elosed, and if $d$ also is shut, the weight will remain motionless. 'The string $i$ is next connected with the slide, and the telescope turned on the moon. As soon as the slide is adjusted in angular position (page 36) the stopeock $d$ is opened, until the weight $c$ moves downwards, at a rate that matches the moon's apparent motion.

In order to facilitate the rating of the clepsydra, the index rod $e$ is pressed by a spring $l(2)$, against an excentric $l$. As the excentric is turned round, the stopeock $d$ is of course opened, with great precision and delicacy. The plug of this stopcock (3) is not perforated by a round hole, but has a slit. This causes equal move- 
ments in the rod $e$, to produce equal changes in the flow. The rating requires consequently only a few moments.

'The object of the side tube $f$ is to avoid disturbing $d$ when it becomes necessary to refill the cylinder, for when it is once opened to the right rlegree, it hildly requires to be tonched again during a night's work. In order to arrest the downward motion of the piston at any point, a clamp serews on the piston rod, and can be brought into contact with the cylinder head, ats in the figure.

'That this instrument should operate in the best mamner, it is essential to have the interior of the brass cyliuder polished from end to end, and of miform dianeter. If any irregularity should be perceived in the rate of going, it can be cured completcly by taking out the piston, impregnating its leather stuffing witl fine rotten stone and oil, and then rubbing it up and down for five minutes in the cylinder, so as to restore the polish. The piston and cylinder must of course be wiped, and regreased with a mixture of beeswax and olive oil (equal parts) after such an operation. In replacing the piston, the cylinder must be first filled with water, to avoid the presence of air, which would act as a spring.

Although it may be objected that this contrivance seems to be very troublesome to use, yet that is not the case in practice. Even if it were, it so far surpasses any prime mover that I have seen, where the utmost accuracy is needed, that it would be well worth employing.

\section{c. The Sun Camera.}

In taking photographs of the sum with the full aperture of this telescope, uo driving mechanism is necessary. On the contrary, the rliffienlty is rather to arrange the apparatus so that an exposure short enough may be given to the sensitive plate, and solarization of the picture avoided. It is not desirable to reduce the aperture, for then the separating power is lessened. 'Ihe time required to obtain a negative is a very small fraction of a second, for the wary appearance prodnced by atmospheric disturbance is not unfrequently observed sharply defined in the photograph, though these acrial motions are so rapid that they can scarcely be counted. Some kind of shutter that can admit and cut off the solar image with great quickness is therefore necessary.

In front of an ordinary camera $\alpha$, Fig. 36 , attached to the eyepiece holder of the telescope, and from which the lenses have been removed, a spring shutter is fixed.

Fig. 36.

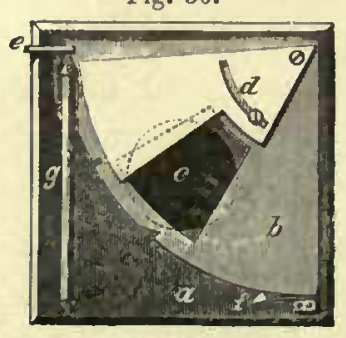

The Spring Shutter. It consists of a quadrant of thin wood $l$, fastened by its right angle to one corner of the cancra. Over the liole in this quadrant a plate of tin $d$ can be adjusted, and held in position by a serew moving in a slot so as to rerluce the hole if desired to a mere slit. It may vary from $1 \frac{1}{2}$ inch to less than $\frac{7}{50}$ of an inch. The quadrant is drawn downwards by an Indiarubber spring $g, 1$ inch wide, $\frac{1}{8}$ of an inch thick, and 8 inches long. 'This spring is stretched when in action to about 12 inches, and when released draws the slit past the aperture $e$ in the camera. Two nicks in the edge of the quadrant serve witl the assistance of a pin $e$, which can easily be drawn out by a lever (not shown in the cut), to confine 
the slit either opposite to or above $c$. A catch at $f$ prevents the shutter recoiling. The sensitive plate is put inside the box as usual in a plate-lolder. When a photograph is taken, the spring shutter is drawn up so that the lower nick in the edge of the quadrant is entered by the pin $e$, and the inside of the camera obscured. 'The front slide of the plateholder is then removed in the usual manner, and the solar inage being brought into proper position by the aid of the telescope finder, the trigger retaining $e$ is touched, the shutter flies past $e$, and the sensitive plate may then be removed to be developed.

'To avoid the very short exposure needed when a silvered mirror of 188 square inches of surface is used, I have taken many solar photographs with an unsilvered mirror, which only reflects according to Bouguer $2 \frac{1}{2}$ per cent. of the light falling upon it, and shonld permit an exposure 37 times as long as the silvered mirror. This is the first time that a plain glass mirror has been used for such a purpose, although Sir John Herschel suggested it for observation many years ago. But eventually this application of the unsilvered mirror luad to be abandoned. It has, it is true, the advantage of reducing the light and heat, but I found that the moment the glass was exposed to the Sun, it commenced to change in figure, and alter in focal length. 'This latter difficulty, which sometimes amounts to half an inch, renders it well nigh impossible to find the focal plane, and retain it while taking out the gromul glass, and putting in the sensitive plate. If the glass were supported by a ring around the edge, and the back left more freely exposed to the air, the difficulty would be lessened but not avoided, for a glass mirror can be raised to $120^{\circ}$ F. on a hot day by putting it in the sunshine, though only resting on a few points. Other means of reducing the light and heat, depending on the same principle, can however be used. By replacing the silvered diagonal mirror with a black glass or plain unsilvered surface, as suggested by Nasmyth, the trouble sensibly disappears.

I have in this way secured not only maculæ and their penumbræ, but also have obtained ficulie almost invisible to observation. On some occasions, too, the precipitate-like or minute flocculent appearance on the Sun's disk was perceptible.

It seems, however, that the best means of acquiring fine results with solar photography, would be to use the telescope as a Cassegranian, and produce an image so much enlarged, that the exposure would not have to be conducted with such rapidity. Magnifying the image by an eyepiece would in a gencral way have the same result, but in that case the photographic advantages of the reflector would be lost, and it would be no better than an achromatic.

\section{§ 4. THE OBSERVATORY.}

'This section is divided into $a$, The Building; $b$, The Dome; and $c$, The Observer's Chair.

\section{a. The Buitding.}

The Observatory is on the top of a hill, 225 fect above low water mark, and is in Latitude $40^{\circ} 59^{\prime} 25^{\prime \prime}$ north, and Longitude $73^{\circ} 52^{\prime} 25^{\prime \prime}$ west from Greenwich, according to the determinations of the Coast Survey. It is near the village of Hastings-upon-Hudson, and is about 20 miles north of the city of New York. The

6 July, 1864. 
surrounding country on the banks of the North River is occupied by country seats, on the slopes and summits of ridges of low hills, and no offensive manufactories

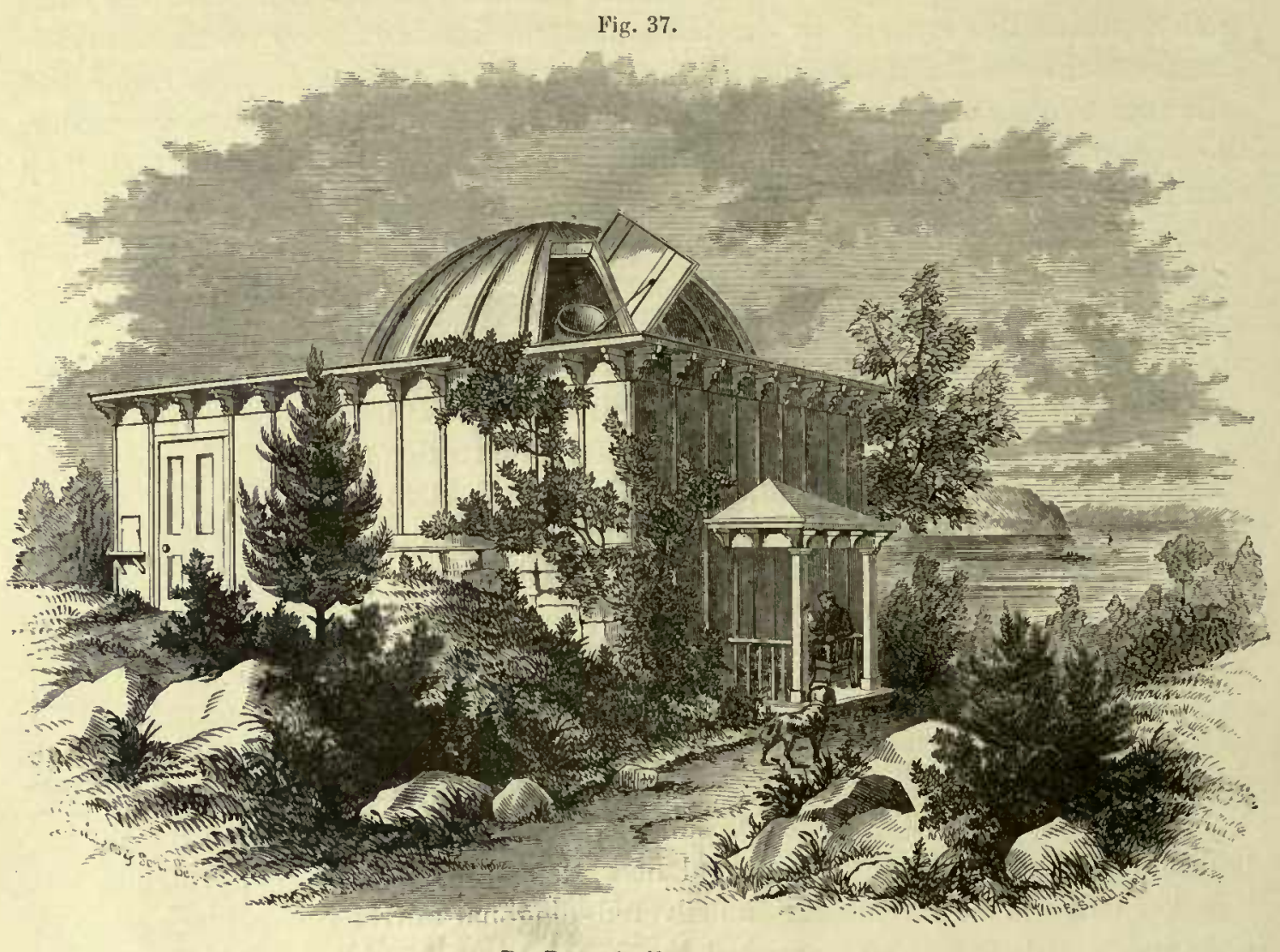

Dr. Draper's Observatory.

vitiate the atmosphere with smoke. Our grounds are sufficiently extensive to exclude the near passages of relicles, and to avoid tremor and other annoyances.

An uninterrupted horizon is commanded in every direction, cxcept where trees near the dwelling house cut off a few degrees toward the southwest. The advautages of the location are very great, and often when the valleys round are filled with foggy exhalations, there is a clear sky over the Observatory, the mist flowing down like a great stream, and losing itself in the chasm through which the Hudson here passes.

The foundation and lower story of the building are excavated out of the solid granite, which appears at the edge of the hill. This arrangement wis intended to keep the lower story cool, and avoid, in the case of the metal reflector, sudden changes of temperature. 'The eastern side of the lower story, lowever, projects over the brow of the hill, and is therefore freely exposed to the air, furmishing, when desired, both access and thorough ventilation through the door. 'The second story or superstructure is of wood, lined inside with boards like the story below. 'They serve to inclose in both cases a non-conducting sheet of air.

The inside dimensions of both stories taken together are $17 \frac{1}{2}$ feet square, and 22 feet high, to the apex of the dome. This space is unnecessarily large for the tele. 
scope, which only requires a cylinder 13 feet in diameter and 13 feet high. A general idea of the internal arrangement is gained from Fig. 28. In Fig. 38, $a a^{\prime}$ is the

Fig. 38.

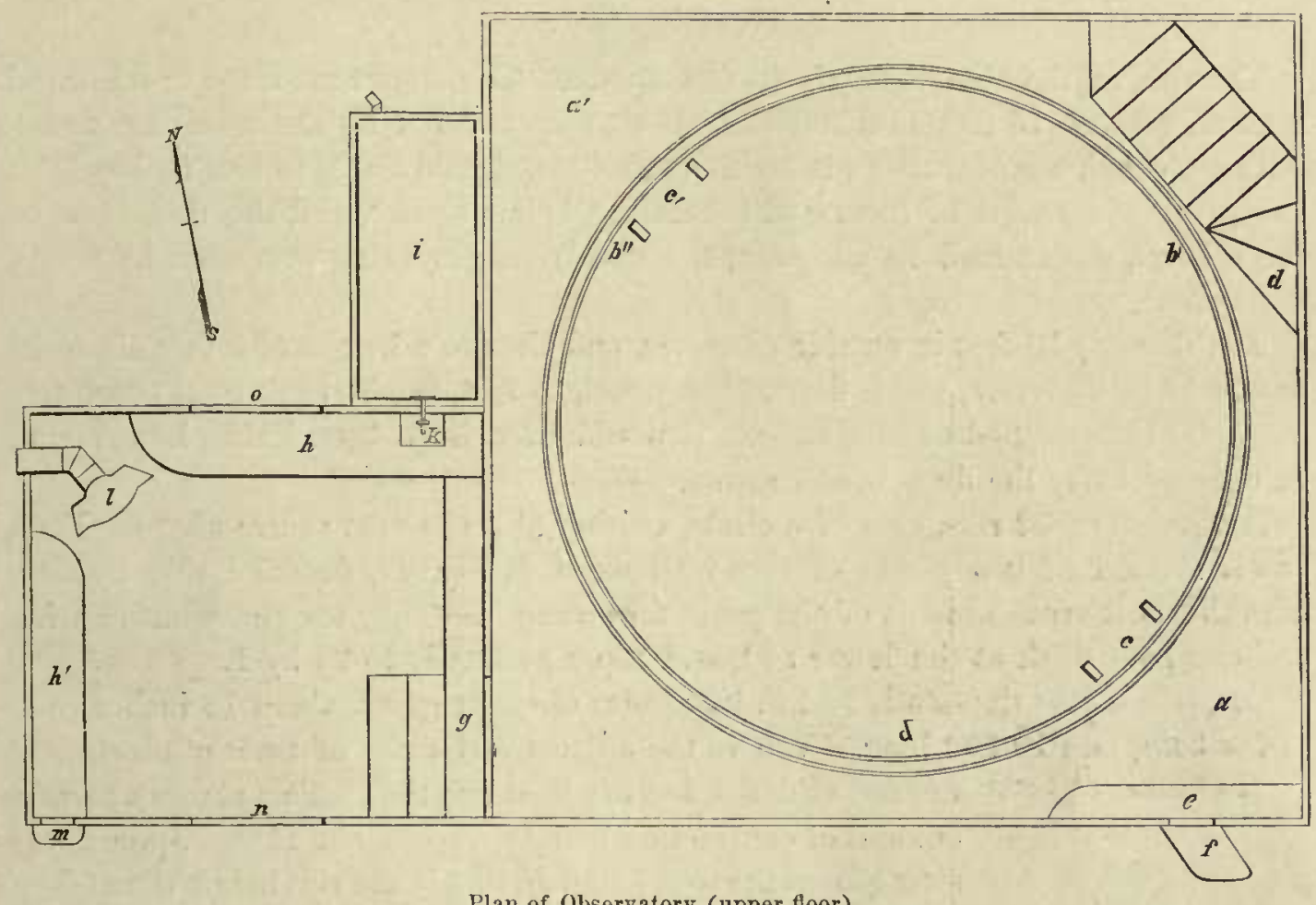

Plan of Observatory (upper floor).

floor of the gallery, $b b^{\prime} b^{\prime \prime}$ the eircular aperture in which the telescope $c a^{\prime}$ turns. 'The stairease is indieated by $d$. The Enlarger, $\$ 6$, rests on the shelf' $e$, the heliostat being outside at $f$. The door going into the photographic room is at $g, h h_{l}$ are tables, $i$ the water tank, $l_{i}$ the tap and $\operatorname{sink}, l$ the stove, $m$ a heliostat shelf, $n$ the door, o the window.

'The building is kept ventilated lyy opening the door in the lower part, and the dome slutter, seen in Fig. 37, for some time before using the instrmment. On a summer day the upper parts, and especially those close under the dome, become without this precantion very hot, and this occurred even before the tin roof was painted. Bright tinplate seems not to be able to reflect by any means all the heat that falls upon it, but will become so warm in July that rosin will melt on it, and insects which lave lighted in a few moments dry up, and soon become pulverizable. A knowledge of these facts led to the abandonment of wooden sheathing under the tin, for withont it when night comes on the accumulated heat radiates away rapidly, and ceases to canse acrial currents near the telescope.

The interior of the building is painted and wainscoted, and the roof is ornamented partly in blue and oak, and partly with panels of tulip-tree wood.

'There are only two windows, and they are near the sonthern angles of the roof. While they admit sumshine on sone occasions, they can on others be closed, and the interior be reducerl to darkness. In the sontheast corner a small opening $e$ 
may allow a solar beam three inches in diameter to come in from a heliostat outside. 'The greatest facilities are thus presented for optical and photographical experiments, for in the latter case the whole room ean be used as a camera obscura.

\section{b. The Dome.}

The roof of the observatory is 20 feet square. The angles are filled in solicl, and a circular space 15 feet in diameter is left to be covered by the revolving dome. Although such a construction is architecturally weak and liable to lose its level, yet the great advantages of having the building below square, and the usefulness of the comers, determined its adoption, the disadvantages boing overcome by a rery light dome.

The dome is 16 feet in outside diameter, and rises to a height of 5 feet above its base. It is, therefore, much flatter than usual, in fact, might have been absolutely flat, with this method of mounting. It would then have been liable, hovever, to be crushed in by the deep winter snows.

It consists of 32 ribs, ares of a circle, uniting at a common centre above. Fach one is formed of two pieces of thin whitewood, b, Fig. 39, fastened side by side, with the best arrangements of the grain for strength. They are three inches wide and one inch thick at the lower end, and taper gradually to $2 \frac{1}{2}$ by 1 .

Over these ribs tinplate is laid in triangular strips or gores, about 18 inches wide at the base, and 10 feet long. Where the adjacent triangles of tin " $a^{\prime}$ mect, they

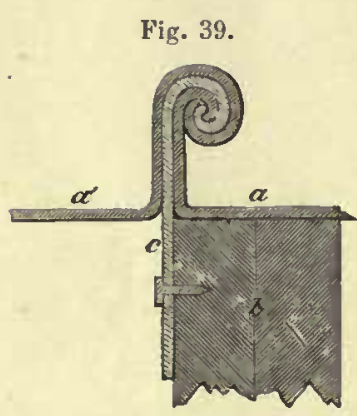

Joints in Tin of Dorne. are not soldered, but are bent together. This allows a certain amount of contraction and expansion, and is witer-proof. It strengthens the roof so much, that if the ribs below were.taken away, this corrugated though thin dome would probably sustain itself. The tin is fastened to the dome ribs $b$ by extril pieces $c$ inserted in the joint and doubled with the other parts, while below they are nailed to the ribs. In the figure the tin is represented very much thicker than it is in reality.

'This dome, although it has 250 square feet of surface, only weighs 250 pounds. 'I'hat at the Cambridge (Massachusetts) Observatory, $29 \frac{1}{2}$ feet in diameter, weighs 28,000 pounds.

'The slit or opening is much shorter than nsual, only extending half way from the base towards the summit. It is in reality an inclined window, $2 \frac{1}{2}$ feet wide at the bottom, $1 \frac{1}{2}$ wide at the top, and 4 feet long. It is closed by a single sluntter, as seen in Fig. 37, and this when opened is sustained in position by an iron rod furnished with a hinge at one end and a hook at the other.

The principal peculiarity of the dome, the means lyy which it is rotated, remains to be described. Usually in such structures rollers or cannon balls are placed at intervals uncler the edge, and by means of rack work, a motion of revolution is slowly accomplished. Here, on the contrary, the whole dome $b b^{\prime} b^{\prime \prime}$ (Fig. 40) is supported on an arch $h l l^{\prime} l^{\prime \prime}$, carrying an axis $a$ at its centre, around which a slight direct force, a pull with a single finger, will canse movenent, and by a sudden push even a quarter of an entire revolution may be accomplished. It is desirable, how- 
ever, to let it rest on the edge $b b^{\prime \prime}$, when not in use. At $c$ there is an iron catch on the arch, by which the lever $e$, that raises the dome, is held down. The fulcrum.

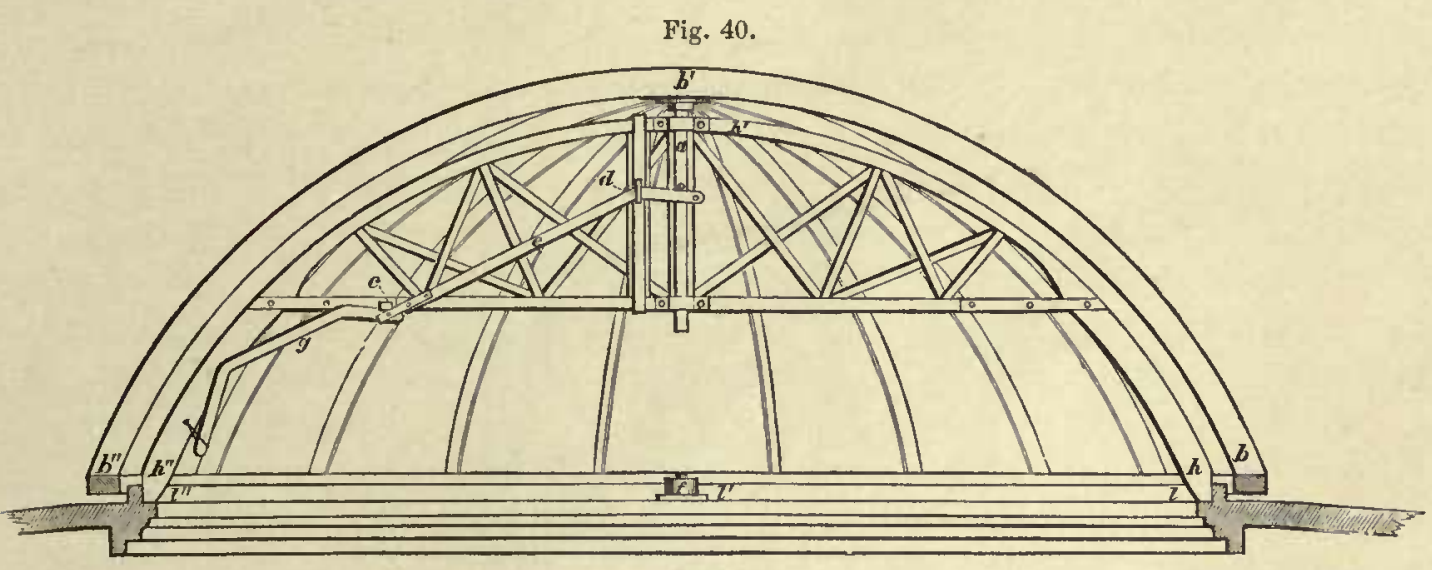

The Dome Arch.

is at $d$. The lever is hinged near $c$, so that when by being depressed it should have come in the way of the telescope below, the lower half $g$ can be pushed up, the part from $c$ toward $d$ still holding the dome supported.

The arch can be set across the observatory in any direction, nortl and south, east and west, or at any intermediate position, becanse the abutments where the ends rest, are formed by a ling $l l^{\prime} l^{\prime \prime}$, fastened round the circular aperture, through the stationary part of the roof.

When the telescope is not in use, and the dome is let down, so that there is no longer an interval of a quarter of an inch between it and the rest of the roof, it is confined inside by four climps and wedges. Otherwise, owing to its lightness, it would be liable to be blown away. These clamps $a$, Fig. 41, are three sides of a square, made of iron one inch square. They catch above by a point in the wooden basis-circle of the dome $b$, and below are tightened by the wedge $c$.

When the dome is raised it is prevented from moving laterally and sliding off by three rollers, one of which is seen at $f$, Fig. 40 . These catch against its imer edge, and only allow slight play. At first it was thought necessary to lave a subsidiary half arch at right angles to the other to hold it up, but that is now removed.

All the parts work very satisfactorily, and owing to

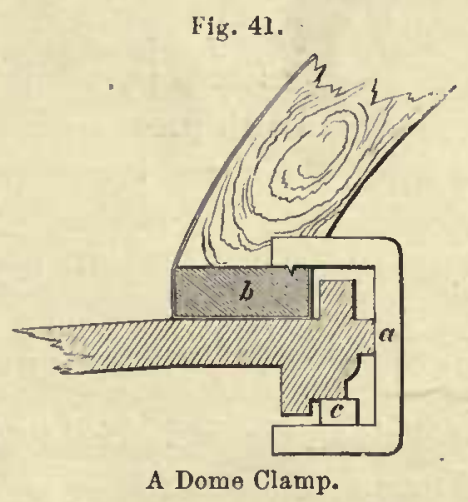
the care taken to get the roof-circle and basis-circle flat and level, no leakage takes place at the joint, and even snow driven by ligh winds is unable to enter.

\section{c. The Observer's Chair.}

This is not a chair in the common acceptation of the word, but is rather a movable platform three feet square, eapable of carrying two or more persons round the observatory, and maintaining them in an invariable position with regard to the tele. scope eyepiece. 
Its general arrangement is better comprehended from the sketch, Fig. 42, than from a labored description. Below, it rums on a pair of wheels a (one only is

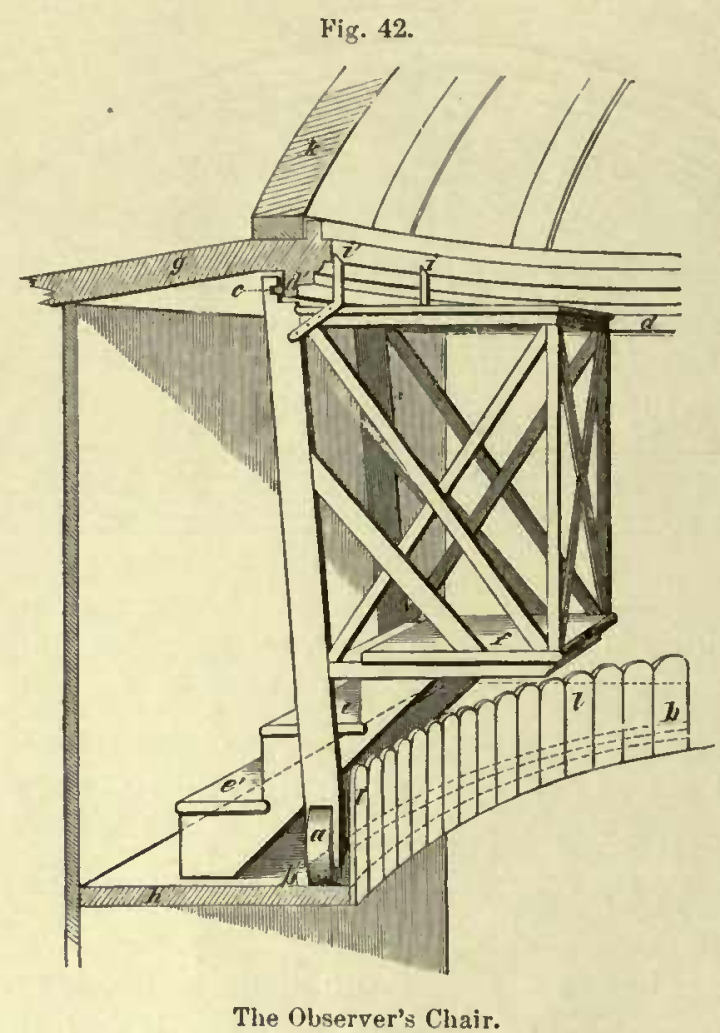

visible) 9 inches in diameter, whose axles point to the centre of the circle upon which they run. They are prevented from shifting outwards by a wooden rail road $l, b^{\prime}$, and inwards by the paling $7, l^{\prime}$. Above, the chair moves on a pair of small rollers $c$, which press against a circular strip) or track $d$, $d$, nailed around the lower edge of the dome opening. Access to the platform is gained by the steps $e, e^{\prime}$. Attached to the railing of this platform, and near it on the telescope, are two tables (not shown in the figure) for eyepieces, the sliding plateholder, \&e.

\section{§ 5. 'TIIE PHO'TOGRAPHIC LABORATORY.}

This section is divided into $a$, Description of the Apartment; and $b$, Photographic Processes.

\section{a. Description of the Apurtment.}

The room in which the photographical operations are carried on, adjoins and connects with the observatory on the sonthenst, as is shown in Figs. 28 and 38. It is 9 by 10 feet inside, and is supplied with shelves and tables rumning nearly all the way round, which have upon them the principal chemical reagents. It is furnished, too, with an opening to admit, from a heliostat outside, a solar beim of any size, up to three inches in diameter.

The supply of water is derived from rain falling on the roof of the building; and 
rumning into a tank $i$, Fig. 38, which will contain a ton weight. The roof exposes a surfice of 532 square feet, and consequently a fall of rain equal to one inch in depth, completely fills the tank. During the course of the year the fall at this place is about 32 inches, so that there is always an abundance. In order to kecp the water free from contamination, the roof is painted with a ground mineral compound, which liardens to a stony consistence, and resists atmospheric influences well. The tank is lined with lead, but having been in use for many years for other purposes, is thoroughly coated inside with various salts of lead, sulphates, \&c. In addition the precaution is taken of emptying the tank by a large stopcock when a rainstorm is approaching, so that any accumulation of organic matter, which can reduce nitrate of silver, may be avoided. It has not been found feasible to use the well or spring water of the ricinity.

'The tank is placed close inder the eaves of the building, so as to gain as much head of water as is desirable. From near its bottom a pipe terminating in a stopcock $k$, lig. 38, passes into the Laboratory. In the northeast comer of the room, and under the tap is a sink for refuse water and solutions, and over which the negatives are developed. It is on an average about twelve fect distant from the telescope. In another corner of the room is a stove, resembling in construction an open fireplace, but sufficient nevertheless to raise the temperature to $80^{\circ} \mathrm{F}$. or higher, if necessary. As a provision against heat in summer, the walls and roof are double, and a free space with numerous openings above is left for circulation of air, drawn from the foundations. The roof is of tinplate, fastened directly to the rafters, without sheathing, in order that heat may not accumulate to sucl an extent during the day as to constitute a source of disturbance when looking across it at night.

For containing negatives, which from being unvarnisher require particular care, there is at one side of the room a case with twenty shallow drawers each to hold eightcen. They accumulate very rapidly, and were it not for frequent reselections the case would soon be filled. On some nights as many as seventecn negatives have been taken, most of which were worthy of preservation. Not less than 1500 were made in 1862 and ' 63.

\section{b. Photographic Processes.}

In photographic manipulations I have had the advantage of my father's long continued experience. He worked for many years with bromide and chloride of silver in his photo-chemical researches (Jommal of the Franklin Institute, 1837), and when Daguerre's beantiful process was published, was the first to apply it to the taking of portraits (Phil. Mag., June, 1840) in 1839; the most important of all the applications of the art. Subsequently he made photographs of the interference spectrum, and ascertained the existence of great groups of lines $M, N, O, P$, above $I I$, and totally invisible to the naked eye (Phil. Mag., May, 1843). 'The importance of these results, and of the study of the structure of flames containing various clementary bodies, that he made at the same time, are only now exciting the interest they descrve.

In 1850, when his work on Physiology was in preparation, and the numerous illustrations had to be produced, I learnt microscopic photography, and soon after 
prepured the materials for the collorion process, then recently invented by Scott Archer. We produced in 1856 many photographs umder a power of 700 diameters, by the means described in the next section.

At first the usual processes for portrait photograpliy were applied to taking the Moon. But it was soon found necessary to abandon these and adopt others. When a collodion negative has to be enlarged-and this is always the case in lunar photography, where the original picture is taken at the focus of an object glass or mirror -imperfections invisible to the naked cye assume an importance which causes the rejection of many otherwise excellent pietures. Some of these imperfections are pinholes, coarseness of granulation in the reduced silver, liability to stains and markings, spots produced by dust.

These were all avoided by washing off the free nitrate of silver from the sensitive plate, before exposing it to the light, and again submitting it to the action of water, and dipping it back into the nitrate of silver bath before developing. 'The quantity of nitrate of silver necessary to development when pyrogallic acirl is used, is however better procured by mixing a small quantity of a standard solution of that salt with the acid.

The operation of taking a lunar negative is as follows. The glass plates $2 \frac{3}{1} \times 3 \frac{1}{1}$ inches are kept in nitric acid and water until wanted. They are then washed under a tap, being well rubbed with the fingers, which have of comrse been properly cleaned. 'They are wiped with, a towel kept for the purpose. Next a few drops of iodized eollodion are poured on each side, and spread with a piece of cotton flamel. They are then polished with a large piece of this flumel, and deposited in a close dry plate box. This system of cleaning with collorlion was suggested by Major Russel, to whose skilful experiments photography is indebted for the tamin process. It certainly is most effective, the drying pyroxyline removing every injurious impurity. 'I'here is never any trouble from dirty plates.

'The stock of plates for the night's work, a dozen or so, being thus prepared, one of them is taken, and by movement through the air is freed from fibres of cotton. It is then coated with filtered collodion being held near the damp sink: The coited plate, when sufficiently dry, is immerserl in a 40 grain nitrate of silver bath, acidified with nitric acid until it reddens litmus paper. 'The exact amount of acid in the bath makes in this "Washed Plate Process" but little difference. When the iorlide and bromide of silver are thoroughly formed the plate is removed, clained for a moment, and then held under the tap till all greasiness, as it is called, disappears. Both front and back receive the current in turn.

It is then exposed, being carried on a little wooden stand, Fig. 43, covered with filtering paper to the telescope, and deposited on the sliding plateholder which has been set to the direction and rate of the moon, while the plate was in the bath. 'The time of exprosure is ascertained by counting the beats of a half-second penslulum.

'The method by which exposure without causing tremor is accomplished, is as follows: A yellow glass slides through the eyepiece-holder, Fig. 33, just in front of the sensitive plate, and is put in before the plate. 'The yellow-colored moon is centred on the collodion film, and the clepsydra and slide are set in motion, the 
mass of the telescope being at rest. A pasteboarrl screen is put in front of the telescope, and the yellow glass taken out. After 20 seconds the instrument remaining still untouched and motionless, the screen is withdrawn, and as many seconds allowed to elapse as desirable. The screen is then replaced and the plate taken back to the photographic room.

After being again put under the tap to remove any dust or impurity, it is clipper into the nitrate bath for a few seconds. 'T'wo drachms of a solution of protosulphate of iron 20 grains, acetic acid 1 drachm, and water 1 ounce, is poured on it. As soon as the image is fairly visible this is washed off, and the development continued if necessary with a weak solution of pyrogallic acid and citro-nitrate of silver-pyrogallic and Fig. 43. citric acids each $\frac{1}{5}$ grain, nitrate of silver $\frac{1}{11}$ grain, water 1 drachm. In order to measure these small quantities standard sohtions of the substances are marle, so that two drops of each contain the desired amomnt. 'They are kept in bottles, through the corks of which pipettes descend to just-below the level of the liquid. 'This avoids all necessity of filtering, and yet no blemishes are produced by particles of floating matter.

During the earlier part of the developinent, when the protosulphate of iron is on the film, an aceurate julgment can be formerl as to the proper length of time for the exposure in the telescope. If the image appears in 10 seconels, it will acquire an appropriate density for enlargement in 45 seconds, and will have the minimum of what is called Pipetle Bottle. fogging and the smallest granulations. If it takes longer to make its first appearance the exposure must be lengthened, and vice versa.

'The latter part of the development, when re-development is practised, is purposely made slow, so that the gradation of tones may be varied by changing the proportion of the ingredients. As it wonld be tiresome and uncleanly to lold the plates in the land, a simple stand is used to keep them level. It consists of a piece of thin wood $a$, Fig. 45 , with an ordinary wood serew, as at $b$, going throngh each corner. Fomr wooden pegs, as at $c$, furnish a support for the plate $\pi$. By the aid of this contrivance and the

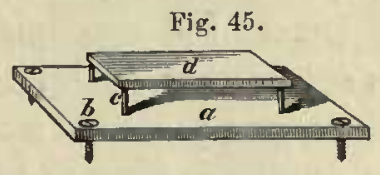

Developing Stand. washing system, I selelom get my fingers marked, and what is much more important, rarely stain a picture.

When the degree of intensity most suitable for subsequent enlargement is reached, that is, when the picture is like an overclone positive, the plate is again flooded with water, treated with cyanicle of potassium or hyposulphite of soda, once more washed and set upon' an angle on filtering paper to dry. It is next morning labelled, and put away unvarnished in the case.

To the remark that this process implies a great deal of extra trouble, it can only be replied that more negatives can be taken on each night than can be kept, and that, even were it not so, one good picture is worth more than any number of bad ones.

Although the above is the method at present arlopted, and by which excellent results have been obtained, it may at any moment give place to some other, and is indeed being continually modified. 'The defects it presents are two-first, the time 
of exposure is too long, and second, there is a certain amount of lateral diffinsion in the thickness of the film, and in consequence a degree of sharpmess inferior to that of the image produced by the parabolic mirror. 'The shortest time in which the moon has been taken in this observatory has been one-third of a second, on the twenty-first day, but on that occasion the sky was singularly elear, and the intrinsic splendor of the light great. The full moon under the same circumstances would have required a much shorter exposure. A person, however, who has put his eye at the focus of such a silvered mirror will not be surprised at the shortness of the time needed for impressing the bromo-iodide film; the brilliancy is so great that it impairs vision, and for a long time the exposed eye fails to distinguish any moderately illuminated object. 'The light from 188 square inches of an almost totil reflecting surface is condensed upon 2 square inches of sensitive plate.

Occasionally a condition of the sky, the reverse of that mentioned above, occurs. The moon assumes a pale yellow color, and will continue to be of that non-actinic tint for a month or six weeks. 'This phenomenon is not confined to special localities, but may extend over great tracts of country. In August, 1862, when our regiment was encamped in Virginia, at Harper's Ferry, the atmosphere was in this condition there, and was also similarly affected at the observatory, more than 200 miles distant. As to the cause, it was not forest or prairie fires, for none of them of sufficient magnitude and duration oceurred, but was probably dust in a state of minute division. No continued rain fell for several weeks, and the clay of the Virginia roads was turned into a fine powder for a depth of many inches. 'The Upler Potomac river was so low that it could be erossed dry-shod. On a subsequent occasion when the same state of things occurred again, I exposed a series of plates (whose sensitiveness was not less than usual, as was proved by a standard artificial flame) to the image of the full moon in the $15 \frac{1}{2}$ inch reflector for 20 seconds, and yet obtained only a moderately intense picture. This was 40 times as long as conmon.

Upon all photographic pictures of celestial objects the influence of the atmospliere is seen, being sometimes greater and sometimes less. 'To obtain the best impressions, just as steady a night is necessary as for critical observations. If the image of Jupiter is allowed to pass across a sensitive plate, a streak almost as wide as the planet is left. It is casily seen not to be continuous, as it would have been were there no atmospheric disturbances, but composed of a set of pirtially isolated images. Besicles this planet, I have also taken impressions of Venus, Mars, double stars, \&c.

An attempt has been made to overcome lateral diffusion in the thickness of the film by the use of dry collodion plates, more particularly those of Major Russel and Dr. Hill Norris. 'These present, it is true, a finc and very thin film during cxposure, lut while developing are so changed by wetting in their mechanical condition that no advantage has resulted. It was while trying them, that I ascertained the great control that hot water exercises over the rapidity of development, and time of exposure, owing partly no doubt to increase of permeability in the collodion film, but also partly to the fact that chemical decompositions go on more rapidly at ligher temperatures. I have attempted in vain to develop a tamin plate when it and the solutions used were at $32^{\circ} \mathrm{F}$, and this though it had had a hundred times the exposure to light that was demanded when the plate was kept at $140^{\circ} \mathrm{F}$. by warm water. 
Protochloride of palladium, which I introduced in 1859, is frequently employed when it is desired to increase the intensity of a negative without altering its thickness. This substance will augment the opacity 16 times, without any tendency to injure the image or produce markings. It is only at present kept out of general use by the scarcity of the metal.

\section{§ 6. 'THE PHOTOGRAPIIC FNIARGER.}

'Two distinet arrangements are used for enlarging, $a$, for Low Powers varying from 1 to 25 ; and $b$, for High Powers from 50 to 700 diameters.

\section{a. Low Powers.}

The essential feature in this contrivance is an entire novelty in photograpnic enlargement, and it is so superior to solar cameras, as they are called, that they are never used in the observatory now. It consists in employing instead of an achromatic combination of lenses, a mirror of appropriate curvature to magnify the original negatives or objects. 'The advantages are casily enumerated, perfect coincidence of visual and chemical foci, flat ficld, absolute sharpness of definition. If the negative is a fine one, the cnlarged proofs will be as good as possible.

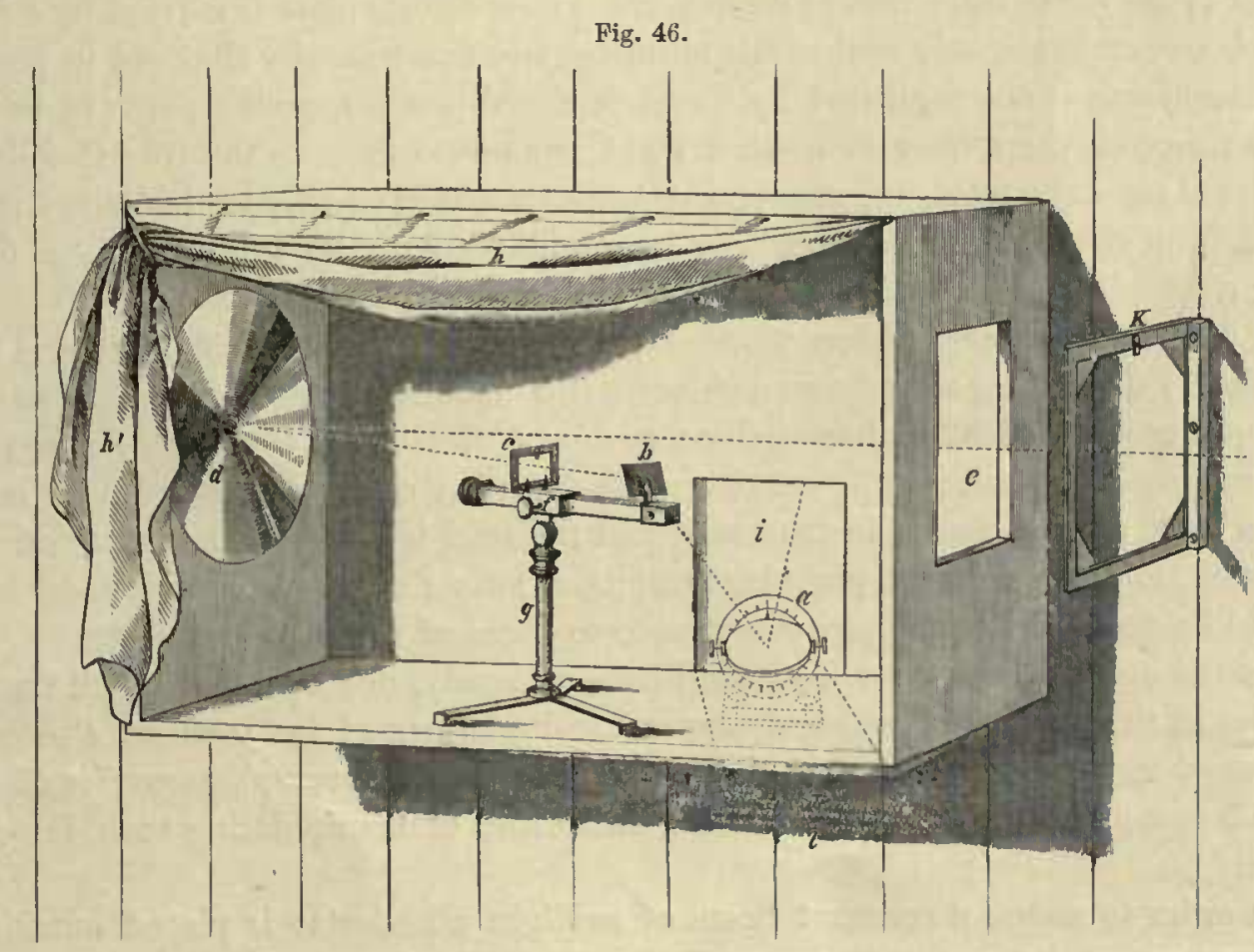

The Photographic Enlarger.

The mirror is of 9 inches aperture, and $11 \frac{1}{2}$ inches focal length. It was polished on my machine to an elliptical figure of 8 fect distance between the conjugate foci, and was intended to magnify 7 times. At first the whole mirror was allowed to officiate, the object being illuminated by diffused daylight. But it was soon ap- 
parent, that although a minute object placed in one focus was perfectly reproduced at the other, seven times as large, yet a large one was not equally well defined in all its parts.

I determined then to produce the enlarged image by passing a solar-bean $1 \frac{1}{2}$ inch in diameter through the original lunar negative-placed in the focus nearest to the mirror-and allowing it to fall on a portion of the concave mirror, $1 \frac{1}{2}$ inch in diameter, at one side of the vertex. Being reflected, it returns past the negative, and goes to form the magnified image at the other focus of the ellipse.

In Fig. 46, $a$ is the lieliostat on a stone shelf ontside; $b$ a silvered glass mirror, to direct the parallel ralys through $e$, the negative; $d$ is the elliptical mirror; $e$ an aperture to be partly closed by diaphragms; $f$ a rackwork movement carried by the tripod $g$; the curtain $h h^{\prime}$ shuts out stray light from the interior of the observatory. The aperture $i$ is also diaphragmed, but is shown open to indicate the position of the heliostat, the shelf of which joins the outside of the building at 7 . 'The dotted line points out the course of the light, which coming from the sun falls on the heliostat mirror $a$, then on $b$, through $c$ to $d$, and thence returning through $e$ to the sensitive plate in the plate loolder $k$.

The distance of this last can be made to vary, being either two feet or twentyeight feet from $d$. In the latter case a magnifying power of about 25 results, the moon being made three feet in diameter. 'The sensitive plate is carried by a frame, which screws to the side wall of the building, and can be easily changed in position. 'The focussing is accomplished by the rack $f$. Where so small a part ( $1 \frac{1}{2}$ inch) of the surface of the mirror is used, a rigid adherence then to the true foci of this ellipse is not demanded, the mirror seeming to perform equally well whether magnifying 7 or 25 times. 'Theoretically it would seem to be limited to the former power.

If instead of placing a lunar photograph, which in the nature of the case is never absolutely sharp, at $c$, some natural object, as for instance a section of bone, is attached to the frame moved by $f$, then under a power of 25 times it is as well defined as in any microscope, while at the same time the amount of its surface seen at once is much larger than in such instruments, and the field is flat. If the intention were, bowever, to make microscopic photographs, a mirror of much shorter focal length would be desirable, one approaching more to tliose of Amici's microscopes.

By the aid of a concave mirror used thus obliquely, or excentrically, all the difficulties in the way of enlarging disappear, and pictures of the greatest size can be produced in perfection. I should long ago have made lumar photographs of more than 3 feet in diameter, except for the difficulties of manipulating such large surfaces.

In order to secure a constant beam of sunlight a heliostat is placed outside the observatory, at its southeast corner $f$, Fig. 38. 'This beam, which can be sent for an entire day in the direction of the earth's axis, is intercepted as shown at $b$, Fig. 46 , and thus if needed an exposure of many hours could be given. The interior of the observatory and photographic room being only illuminated by faint yellow rays, no camera box is required to cut off stray light. 'The eye is by these means liept in a most sensitive condition, and the focussing can be effected with the critical 
accuracy that the optical arrangement allows, no correction for chromatic aberration being demanded.

I have made all the parts of this apparatus so that they can be easily separated or changed. 'The flat mirrors are of silvered glass, and are used with the silvered side toward the light, to awoid the double image produced when reflection from both sides of a parallel plate of glass is permitted. The large concave mirror happens to be of speculnm metal, but it can be repolished if necessary by means of a four inch polisher, passed in succession over every chord of the face. A yellow film of tarnish easily accumulates on metal specula if they are not earefully kept, and decreases their photographic power seriously.

Of the muling of Reverses. - In addition to the use of the Enlarger for magnifying, it is found to have important advantages in copying by contact. The picture of the image of the moon produced in the telescope is negative, that is, the lights and shades are reversed. In enlarging such a negative reversal again takes place, and a positive results. This positive cannot, however, be used to make prints on paper, hecanse in that operation reversing of light and shade once more oceurs. It is necessary then at some stage to introduce still another reversal. 'This may be accomplished either by printing from the original negative a positive, which may bc enlarged, or else printing from the enlarged positive a negative to make the paper proofs from. In either case a collodion film, properly sensitized, is placed behind the positive or negative, and the two exposed to light.

If diffinsed light or lamplight is used, the two plates must be as closely in coritact as possible, or the sharpmess of the resulting proof is greatly less than the original. This is because the light finds its way through in many various directions. If the two plates, however, are placed in the cone of sunlight coming from the Enlarger, and at a distance of fifteen or twenty feet from it, the light passes in straight lines and only in one direction through the front picture to the sensitive plate behind. I have not been able to see under these cireumstances any perceptible diminution in sharpness, though the plates had been $\frac{1}{1} \frac{1}{6}$ of an inch apart. It is perfectly feasible to use wet collodion instead of dry plates, no risk of scratching by contact is incurred, and the whole operation is easily and quickly performed. The time of exposure, 5 sceonds, is of convenient length, but may be inereased by putting a less reflecting surface or an unsilvered glass mirror in the heliostat. A diaphragm with an aperture of half an inch if placed at e, Fig. 46, to shut out needless light, and avoid injuring the sharpness of the reverse by diffusion throngh the room. In enlarging other diaphragms are also for the same reason put in the place of this one. For a half moon for instance, a yellow paper with a half circular aperture, whose size may be found by trial in a few minutes, is pinned against $e$.

'The enlarged pietures obtained by this apparatus are much better than can be obtained by any other method known at present. 'The effect, for instance, of a portrait, made life-size, is very striking. Some astronomers have supposed that advantages would arise from taking original lumar negatives of larger size in the telescope, that is, from enlarging the image two or three times by a suitable eyepiece or concave archromatic, before it reached the sensitive plate. But apart from the fact that a reflector would then have all the disadvantages of an achromatic, 
the atmospheric difficulties, which in reality constitute the great obstacle to success, would not be diminished by such means. 'The apparent advantage, that of not magnifying defects in the collorlion, is not of much moment, for when development of the photographs is properly conducted, and thorough cleanliness practised, imperfections are not produced, and the size of the silver granules is not oljectionable.

\section{b. High Powers.}

Although negatives of astronomical objects lave not as yet been marle which could stand the high powers of the arrangement about to be describer, yet they bear the lower powers well, and give promise of improvement in the future.

Photography of microscopic objects as usually described, consists in passing a beam of light through the transparent object into the compound body of the microscope, and receiving it on its exit from the eyepiece upon a ground glass or sensitive plate. 'The difficulty which besets the instrument generally, and interferes with the production of fine results, arises from the uncertainty of ascertaining the focus or place for the sensitive plate. For if the collodion filu be put where the image on ground glass secms best defined, the resulting photograph will not be sharp, becanse the actinic rays do not form their image there, but either farther from or nearer to the lenses, depending on the amount of the chromatic correction given by the optician. Practically by repeated trials and variation of the place of the sensitive compound, an approximation to the focus of the rays of maximum photographic intensity is reached.

Fig. 47.

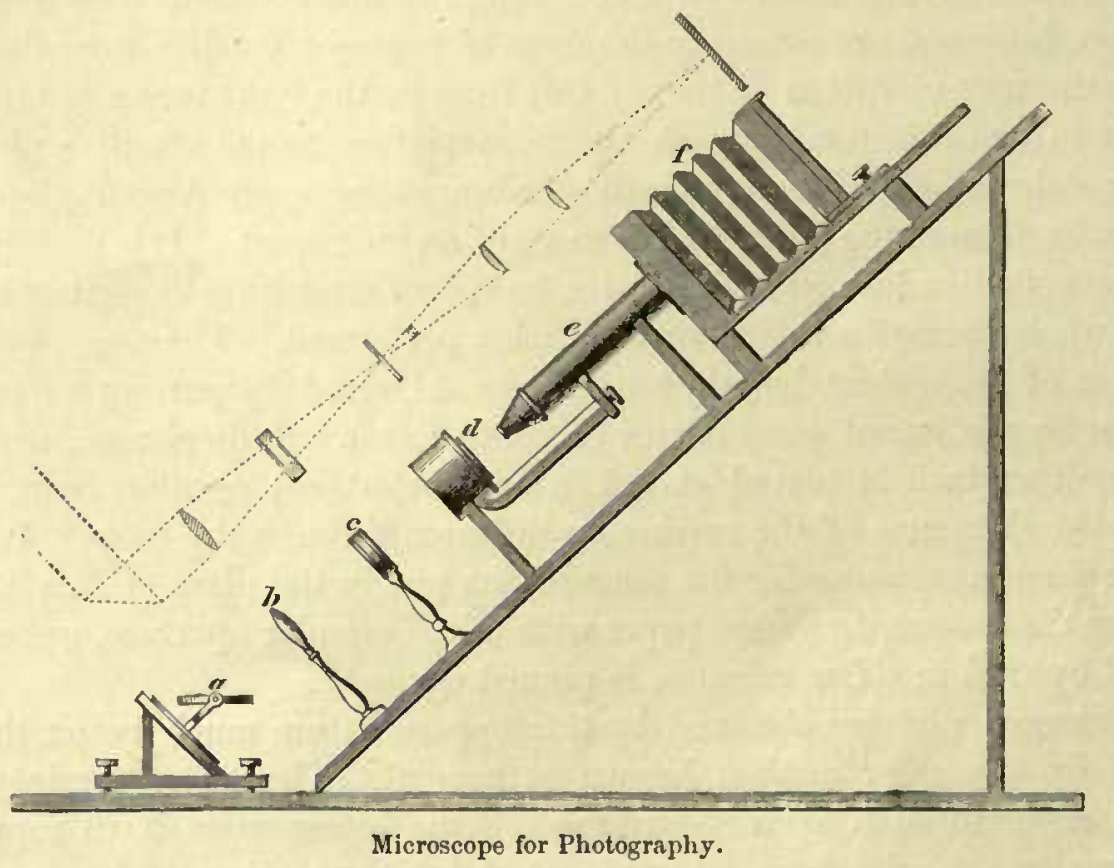

During my father's experiments on light, and more particularly when engaged in the invention of portrait photography, he found that the ammonio-sulphate of copper, a deep biue liquid, will separate the more refrangible rays of light, the rays 
concerned in photography, from the rest. If a beam of sunlight be passed through such a solntion, inclosed between parallel plates of glass, and then condensed upon an object on the stige of a microscope, a blue colored image will be formed on the ground glass, above the eyepiece. If the place of best definition be carefully ascertained, and a sensitive plate put in the stead of the ground glass, a sharp photograph will always result.

Besides, there is no danger of burning up the object, as there would be if the mabsorbed sunlight were condensed on it, and hence a much larger beam of light and much ligher powers can be used. The best results are attained when an image of the sun prodnced by a short focussed lens is made to fall upon and coincide with the trausparent object. In 1856 we obtained photographs of frog's blood disks, navicula angulata, and several other similar objects under a power of 700 diameters, excellently defined. Since then several humdreds of microscopic pictures have been taken.

In the figure, $c$ is the heliostat, $b$ a lens of three inches aperture, $c$ the glass cell for the ammonio-sulphate of copper, $d$ the object on the stage of the microscope $e$, $f$ the camera for the ground glass or sensitive plate. Above the figure the course of the rays is shown by dotted lines.

In concluding this account of a Silvered Glass Telescope I may answer an inquiry which doubtless will be made by many of my readers, whether this kind of reflector can ever rival in size and efficiency such great metallic specula as those of Sir William Hersehel, the Earl of Rosse, and Mr. Lassell? My experience in the matter, strengthened by the recent successful attempt of $\mathbf{M}$. Foucault to figure such a surface more than thirty inches in diameter, assures me that not only can the four and six feet telescopes of those astronomers be equalled, but even excelled. It is merely an affair of expense and patience. I hope that the minute details I have given in this paper may lead some one to make the effort.

\section{HASTINGS, WESTCHESTER County,} NEW Үовк, 1863.

Postscript.- Since writing the above I have completed a photograph of the moon 50 inches in diameter. The original negative from which it has been made, bears this magnifying well, and the picture has a very imposing effect.

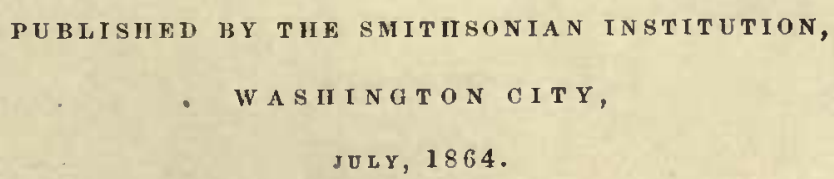







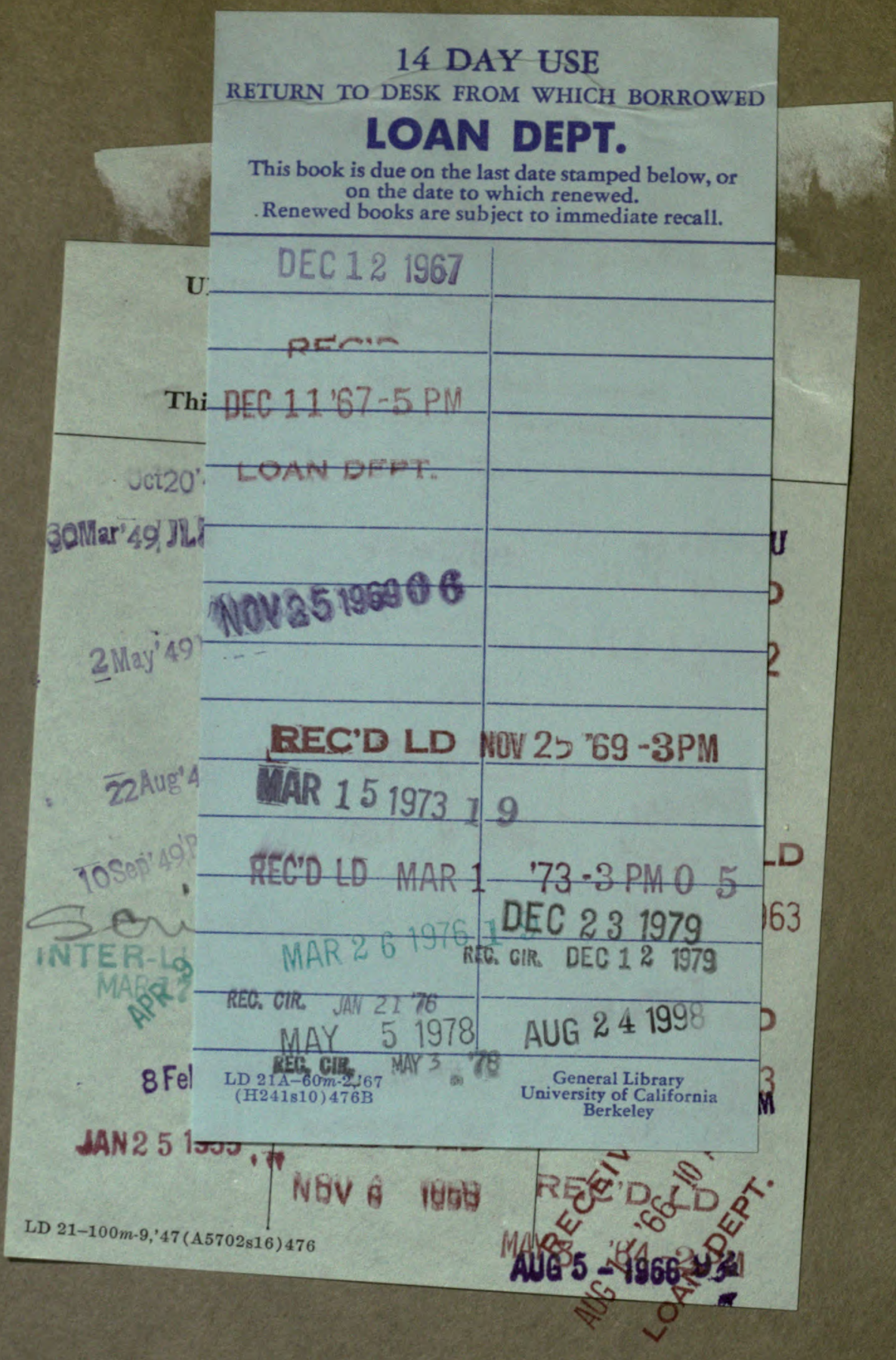



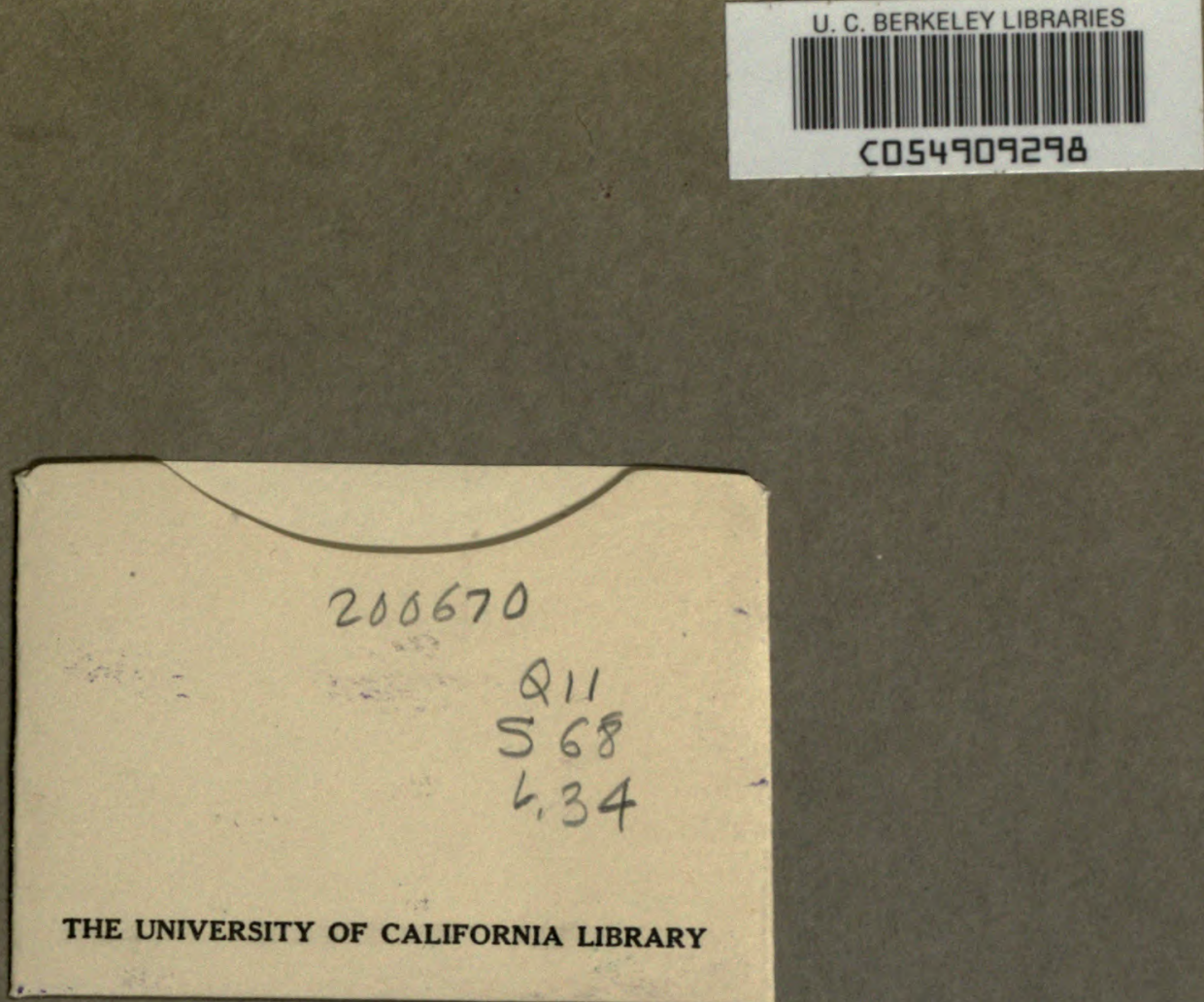
